\title{
A Quality Control Concept for Radar Reflectivity, Polarimetric Parameters, and Doppler Velocity
}

\author{
KATJA Friedrich* AND MARTIN Hagen \\ Institut für Physik der Atmosphäre, Deutsches Zentrum für Luft -und Raumfahrt, Oberpfaffenhofen, Wessling, Germany \\ THOMAS EINFALT \\ einfalt\&hydrotec GbR, Lübeck, Germany
}

(Manuscript received 17 February 2005, in final form 1 January 2006)

\begin{abstract}
Over the last few years the use of weather radar data has become a fundamental part of various applications like rain-rate estimation, nowcasting of severe weather events, and assimilation into numerical weather prediction models. The increasing demand for radar data necessitates an automated, flexible, and modular quality control. In this paper a quality control procedure is developed for radar reflectivity factors, polarimetric parameters, and Doppler velocity. It consists of several modules that can be extended, modified, and omitted depending on the user requirement, weather situation, and radar characteristics. Data quality is quantified on a pixel-by-pixel basis and encoded into a quality-index field that can be easily interpreted by a nontrained end user or an automated scheme that generates radar products. The qualityindex algorithms detect and quantify the influence of beam broadening, the height of the first radar echo, ground clutter contamination, return from non-weather-related objects, and attenuation of electromagnetic energy by hydrometeors on the quality of the radar measurement. The quality-index field is transferred together with the radar data to the end user who chooses the amount of data and the level of quality used for further processing. The calculation of quality-index fields is based on data measured by the polarimetric C-band Doppler radar (POLDIRAD) located in the Alpine foreland in southern Germany.
\end{abstract}

\section{Introduction}

Quality characterization of observational data is one of the most important steps before applying processing algorithms. At the same time, as data quantity and number of various types of applications increase, the demand for automated and flexible quality characterization and correction rises. Since the number of operational weather radar systems has increased over the last few years, radar-based precipitation forecast and severe weather warning systems have become a fundamental part in everyday life, for instance, the Integrated Terminal Weather System (ITWS; Evans and Ducot 1994), the Generating Advanced Nowcasts for Devel-

* Current affiliation: MeteoSwiss, Locarno, Switzerland.

Corresponding author address: Katja Friedrich, MeteoSwiss, Via ai Monti 146, CH-6605 Locarno Monti, Switzerland. E-mail: Katja.Friedrich@meteoswiss.ch opment in Operational Landbased Flood Forecast (GANDOLF; Pierce et al. 2000), or Convection in Radar (CONRAD; Lang 2001). Ongoing research focuses intensively on the use of radar data for assimilation in numerical weather prediction and hydrological models to improve quantitative precipitation forecasts. As part of this goal, the European cooperation in the field of scientific and technical research (COST) Action 717 investigated how to make the best use of radar information (Rossa et al. 2005). This paper presents the work of one part of this COST Action 717 dealing with the quantification of radar data errors. It is based on a survey on user and application requirements conducted by several European weather services.

Weather radars sample reflectivity factor (hereinafter referred to as reflectivity), in some cases Doppler velocity and polarimetric parameters, over a wide horizontal range $(\sim 250 \mathrm{~km})$ with a spatial resolution of several hundred meters and a temporal resolution within minutes. Radar data are often biased by various factors. Echo returns from non-weather-related objects, 


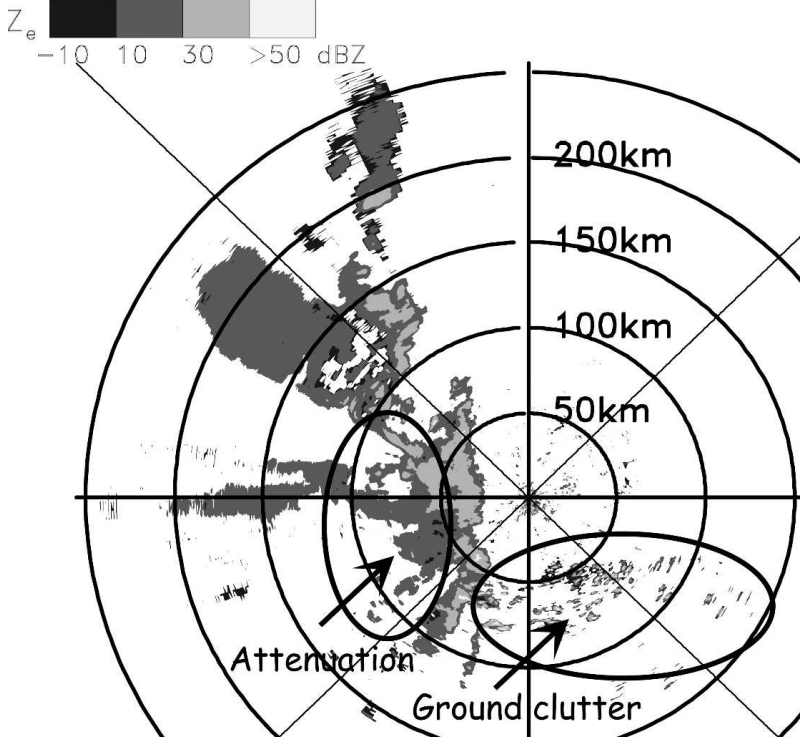

FIG. 1. Reflectivity factor field $\left(Z_{e}\right)$ displayed as PPI at $0.7^{\circ}-$ elevation angle. Measurements were achieved by POLDIRAD (located in the center) at 1953 UTC on 21 Jul 1992. Grayscale for reflectivity is shown at top. Radar measurements are contaminated by ground clutter from the Alps, which are located south of POLDIRAD. Data are also contaminated by attenuation of electromagnetic energy caused by hydrometeors that occur west of the squall line located about $40 \mathrm{~km}$ west of POLDIRAD.

for example, ground and sea clutter, birds, and attenuation of the transmitted electromagnetic wave by hydrometeors, are the main factors contributing to uncertainties in the measurement. Figure 1 shows a reflectivity field during the passage of a squall line measured by the polarimetric diversity C-band Doppler radar (POLDIRAD). The radar is operated by the Deutsche Zentrum für Luft- und Raumfahrt at Oberpfaffenhofen, which is located $30 \mathrm{~km}$ southwest of Munich in Germany. The reflectivity data are contaminated by ground clutter from the Alps south of the radar and attenuation by hydrometeors behind the squall line west of the radar. Those biases affect the data and yield to mismatches in determining radar products like rainrate estimation. A variety of error sources and their impact on radar measurements have been studied intensively and are summarized, for instance, in Battan (1973), Zawadzki (1984), Hannesen (2001), Alberoni et al. (2002), and Meischner (2003), among other studies.

Over the years algorithms have been developed to either detect or correct contaminations. Grecu and Krajewski (2000) and Krajewski and Vignal (2001) for instance developed a methodology for detecting anomalous propagation echoes using neural networks. Data quality of the Next-Generation Weather Radar (NEXRAD) has been constantly optimized using re- flectivity and Doppler velocity in a fuzzy logic-based anomalous propagation clutter mitigation schemes (Kessinger et al. 2003). Steiner and Smith (2002) used the three-dimensional reflectivity structures to detect automatically sea clutter and anomalous propagation either separated from or embedded within precipitation echoes. Sempere-Torres et al. (2003) developed an algorithm to detect signal instabilities of radar measurements by analyzing temporal variations of mountain returns. A correction for precipitation attenuation based on the minimization of a cost function is suggested by Berenguer et al. (2002). Attenuation correction using dual-polarization radar measurements has been discussed by Aydin et al. (1989), Bringi et al. (1990), and Gorgucci et al. (1996). This listing presents only a short extraction of the large number of different radar correction and error detecting algorithms. Processing and scanning techniques have also been improved to overcome certain shortages like Doppler spectrum aliasing, ground clutter contamination, and second-trip echo return. Unal and Moisseev (2004) introduced a simple processing technique for the Doppler analysis combining simultaneous measures required for polarimetry analysis and maximum unambiguous Doppler velocity. Many operational Doppler weather radars operate with a dual-pulse-repetition frequency (dual-PRF) technique in order to extend the unambiguous Doppler velocity interval (Dazhang et al. 1982; Holleman and Beekhuis 2003). Alternatively, a staggered-pulse-repetition frequency allows the increase of the maximum unambiguous velocity while maintaining an adequate unambiguous range (Zrnic and Mahapatra 1985). Phase coding techniques have been employed in order to isolate radar echoes returning from a transmitted pulse at times subsequent to when previous pulses have been transmitted (Sachidananda 1997).

For broader usage in terms of different applications, increasing numbers of measured quantities, and an increasing number of radar systems, most of the aforementioned correction algorithms and processing techniques are lacking in a few key respects. First, they only focused on specific kinds of contamination for specific applications, which complicates the combination of several algorithms. Most algorithms focus on data correction rather than quality characterization. Also, no information about the corrections applied and the quality of the data is provided to the end user or for product generation. Finally, data correction is not standardized at present, and therefore, these procedures may produce different results, even when applying the same basic method.

To properly address these issues, a consistent quality control concept needs to be developed. This is accom- 
plished in this paper by characterizing the quality of radar reflectivity, polarimetric parameters, and Doppler velocity to be used for any application. This concept is unique for the following reasons.

- A consistent strategy is applied on a pixel-by-pixel basis to all three quantities.

- This is the first quality control concept for polarimetric parameters.

- The concept focuses primarily on the quality characterization without applying data modification.

- End users have access to values quantifying the amount of contamination. Therewith, they will be able to choose the amount of data and the level of data quality required for their specific application.

Section 2 describes the concept for the quality control scheme. The determination of quality-index fields is the only part of this concept that is discussed in detail in this paper. The quality characterization for reflectivity is described in section 3 , the quality characterization for polarimetric parameters is described in section 4, and the quality of the Doppler velocity is quantified in section 5. Finally, conclusions are presented in section 6.

\section{Concept for the quality control scheme}

The quality control scheme for radar reflectivity, polarimetric parameters, and Doppler velocity should consist of 1) gross error filtering and recovery of dealiased Doppler velocities or second-trip echoes in order to avoid artificial gradients leading to misinterpretation from automated algorithms and 2) quality control procedures based on a pixel-by-pixel basis. Each individual step is illustrated in the data flow diagram shown in Fig. 2. The quality control scheme is assembled in a modular way, which allows the extension, modification, and omission of algorithms in order to meet user and application requirements (Einfalt et al. 2004). In this paper, the focus is solely on the determination of quality-index fields generated by qualityindex algorithms. The following paragraph describes briefly the main parts of the quality control concept.

The new generation of signal processors already includes a large number of gross error filtering and recovery techniques such as clutter and speckle filtering, filtering and recovery of second-trip echoes, Doppler velocity dealiasing, and a simple quality control [for more information, refer to Sigmet's RVP8 user's manual (Sigmet 2004)]. Since the majority of weather radar systems operate with older signal processors that include only parts of the aforementioned algorithms, filtering and recovery are applied afterward. Large numbers of filtering algorithms have been developed

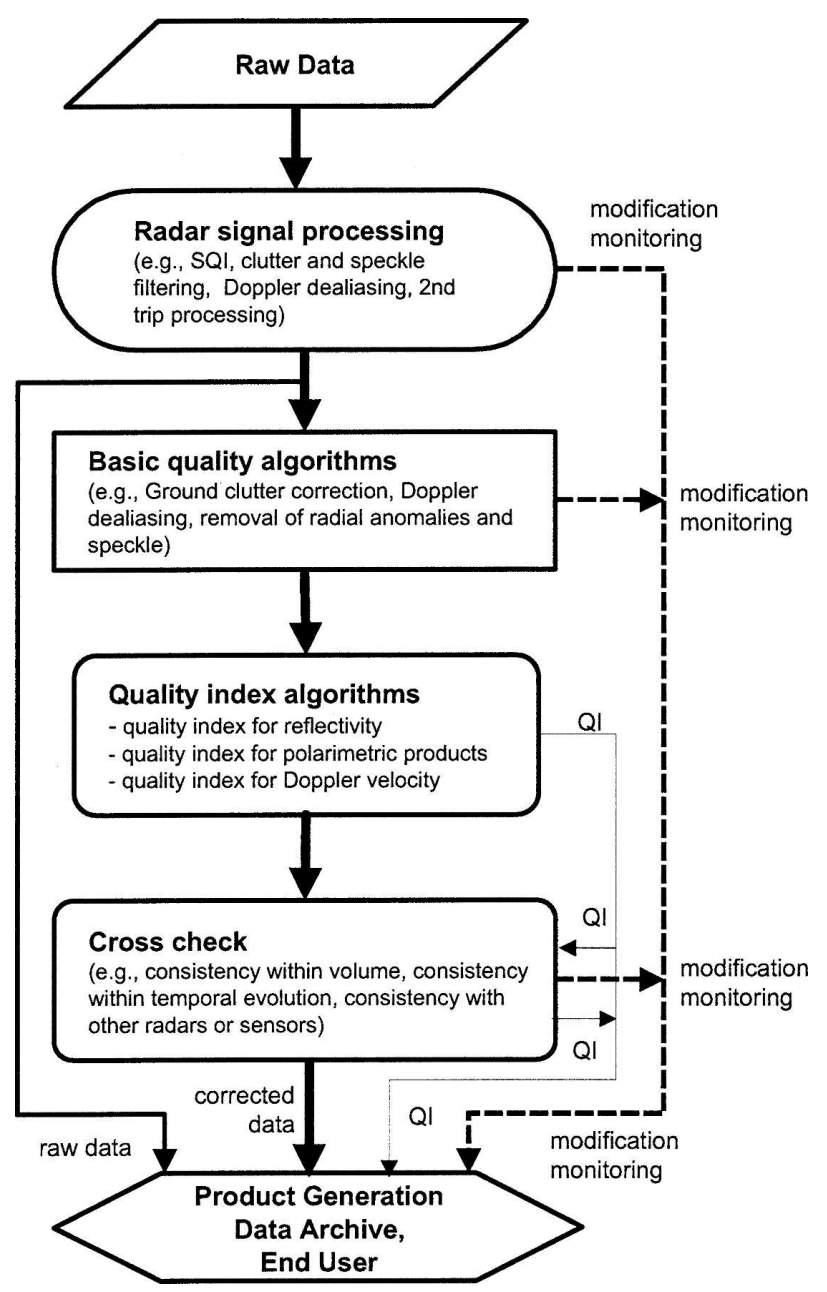

FIG. 2. Data-flow diagram depicting the processing chain for the quality control scheme. Observational data flow is depicted by thick, solid lines; modification monitoring is depicted by thick, dashed lines; the transfer of the quality-index (QI) fields is depicted as thin, solid lines; and raw data transfer is depicted by a solid line. More explanations are found in the text.

and successfully applied for ground clutter (e.g., Joss and Lee 1995; Lee et al. 1995; Sanchez-Diezma et al. 2001), Doppler velocity dealiasing [see, e.g., James and Houze (2001) and Tabary et al. (2001) for an overview], and removal of isolated pixels and radial anomalies (Gabella and Notarpietro 2002). Information about whether the data pixel was eliminated or how it was modified is essential in order to detect algorithm failure and retrace certain pixels. Although it is included in the processing chain in Fig. 2, further research on this topic needs to be addressed.

The quality of the measurement is evaluated by quality-index algorithms that identify and estimate the amount of contamination. The information is encoded on a pixel-by-pixel basis into quality-index fields. The 
TABLE 1. Weighting factor combinations for nowcasting, assimilation, and rain-rate estimation to be applied for different weather situations such as stratiform precipitation, convective precipitation, and a combination of both (denoted as hybrid) for POLDIRAD.

\begin{tabular}{|c|c|c|c|c|c|c|c|c|c|}
\hline & $W_{\text {range }}$ & $W_{\text {shield }}$ & $W_{\text {att }}$ & $W_{\mathrm{vpr}}$ & $W_{\text {bea }}$ & $W_{\text {rain }}$ & $W_{\text {con }}$ & $W_{\mathrm{sq}}$ & $W_{\mathrm{np}}$ \\
\hline \multicolumn{10}{|l|}{ Nowcasting } \\
\hline Stratiform & 1 & $0.5-1$ & $0.4-0.6$ & 0 & 0.5 & 0 & 0 & 1 & 1 \\
\hline Convective & 1 & $0.5-1$ & 1 & 0 & 0.5 & 0 & 0 & 1 & $0.6-0.8$ \\
\hline Hybrid & 1 & $0.5-1$ & 1 & 0 & 0.5 & 0 & 0 & 1 & 0.8 \\
\hline \multicolumn{10}{|l|}{ Assimilation } \\
\hline Stratiform & 1 & $0.8-1$ & $0.4-0.6$ & 0.8 & 0.5 & 0 & 0 & 1 & 1 \\
\hline Convective & 1 & $0.8-1$ & 1 & 0.8 & 0.5 & 0 & 0 & 1 & $0.6-0.8$ \\
\hline Hybrid & 1 & $0.8-1$ & 1 & 0.8 & 0.5 & 0 & 0 & 1 & 0.8 \\
\hline \multicolumn{10}{|c|}{ Rain-rate estimation } \\
\hline Stratiform & 1 & 1 & $0.4-0.6$ & 1 & 1 & 1 & 0.5 & 1 & 1 \\
\hline Convective & 1 & 1 & 1 & 1 & 0.5 & 1 & 1 & 1 & $0.6-0.8$ \\
\hline Hybrid & 1 & 1 & 1 & 1 & 0.5 & 1 & 1 & 1 & 0.8 \\
\hline
\end{tabular}

quality-index schemes for reflectivity, polarimetric parameters, and Doppler velocity are discussed in more detail in the following sections.

The second part in the quality control includes the final check for spatial and temporal consistency (denoted as "cross-check" in Fig. 2). Multiple sensor information, for example, from independent radars, are used to cross-check the radar measurements. An example of a cross-check procedure is given by Friedrich and Hagen (2004) using multiple-Doppler information to detect irregularities in the Doppler velocity measurement. Additional data sources can also include satellite data, surface synoptic stations, radiosoundings, or numerical model output. After the data passed the quality control scheme, radar products can be generated. Missing single rays or small wholes in the radar pictures can be filled applying simple interpolation algorithms (Golz et al. 2004). Data can be smoothed, filtered, or extrapolated. The end user has access to the qualitycontrolled observational data or the generated products, the respective averaged quality-index field, and possibly the modification monitoring field.

\section{Quality-index scheme for reflectivity}

\section{a. Methodology}

Over the years four main factors have been identified that contribute to uncertainties in radar reflectivity measurements:

1) beam broadening and height of the first radar echo (denoted as $F_{\text {range }}$ ),

2) partial or complete beam shielding due to ground clutter (denoted as $F_{\text {shield }}$ ),

3) attenuation of electromagnetic energy by hydrometeors (denoted as $F_{\text {att }}$ ),

4) inhomogeneous vertical profile of reflectivity (denoted as $\left.F_{\mathrm{vpr}}\right)$.

While factors 1 and 2 can be considered persistent, that is, constant for a given radar installation and independent of the weather situation, the type of error denoted as 3 and 4 is an intermittent bias and needs to be calculated separately for each radar volume. The averaged quality-index field for reflectivity, $\bar{F}_{Z_{e}}$, is computed as

$$
\bar{F}_{Z_{e}}=\left\{\begin{array}{l}
0 \text { for } F_{\text {att }}=0 \text { or } F_{\text {shield }}=0 \\
1 / C_{Z_{e}}\left(W_{\text {range }} F_{\text {range }}+W_{\text {shield }} F_{\text {shield }}+W_{\text {att }} F_{\text {att }}+W_{\text {vpr }} F_{\text {vpr }}\right) \quad \text { else }
\end{array}\right.
$$

where

$$
C_{Z_{e}}=W_{\text {range }}+W_{\text {shield }}+W_{\text {att }}+W_{\mathrm{vpr}},
$$

with $W_{\text {range }}, W_{\text {shield }}, W_{\text {att }}$, and $W_{\text {vpr }}$ being the respective weights. Weighting factors are set according to the weather situation, the location of the radar, and the application. Table 1 gives an overview of weighting factor ranges that will be discussed in more detail in the following sections.

Each quality-index field and the average index field range between zero and one. When data are contaminated by ground clutter, indicated as $F_{\text {shield }}=0$, or strongly attenuated by hydrometeors, indicated as 


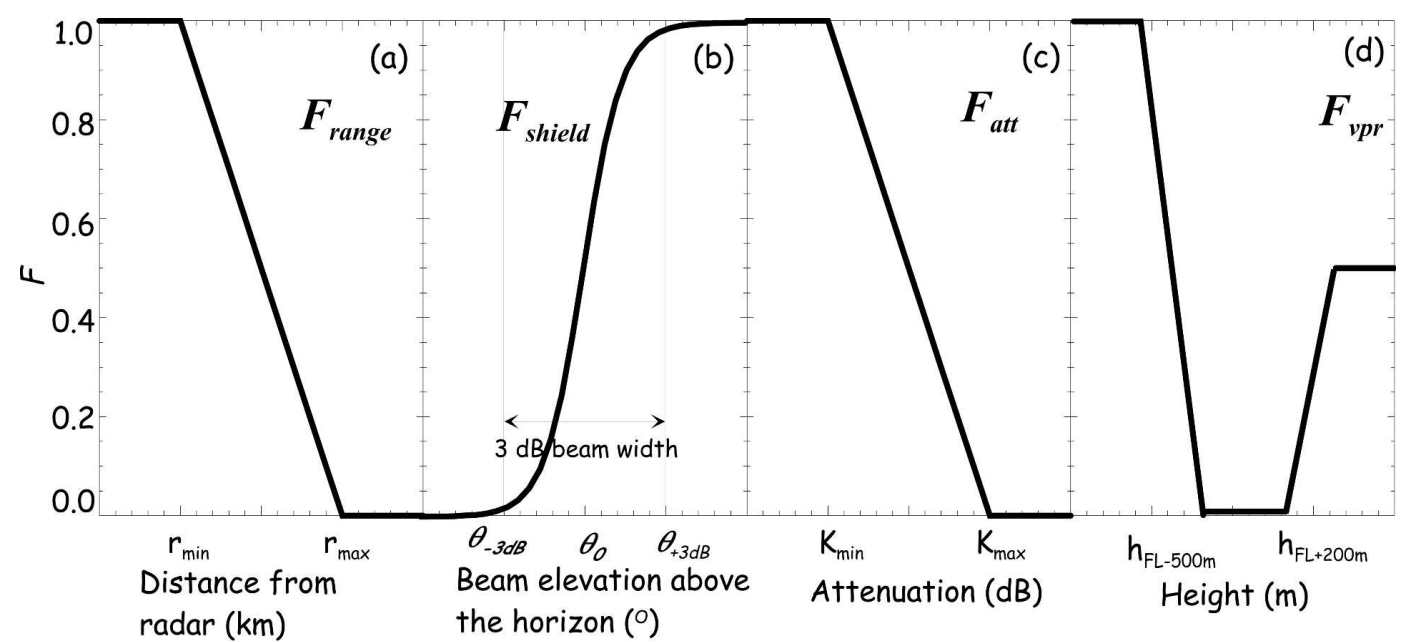

FIG. 3. Computation of the quality-index field (a) $F_{\text {range }}$ based on the influence of range resolution, (b) $F_{\text {shield }}$ based on the amount of beam shielding due to ground clutter, (c) $F_{\text {att }}$ based on the amount of pathlength attenuation, and (d) $F_{\mathrm{vpr}}$ based on the variability of the vertical reflectivity profile. (a) Maximum and minimum sample range are denoted as $r_{\min }, r_{\max }$. (b) The 3 -dB beamwidth is margined by $\theta_{-3 \mathrm{~dB}}$ and $\theta_{+3 \mathrm{~dB}}$. The elevation angle of the mainlobe axis is denoted as $\theta_{0}$. (c) The thresholds for maximum and minimum attenuation are $K_{\max }$ and $K_{\mathrm{min}}$, respectively. (d) The thickness of the melting layer is defined as freezing level plus $200 \mathrm{~m}, h_{\mathrm{FL}+200}$, and freezing level minus $500 \mathrm{~m}$ is denoted as $h_{\mathrm{FL}-500}$.

$F_{\text {att }}=0$, these pixels will not be used for further data processing, and $\bar{F}_{Z_{e}}$ is set to zero. The interpolation from the respective parameter field to the quality-index field is schematically illustrated in Fig. 3. The determination of $\bar{F}_{Z_{e}}$ is exemplified using reflectivity measurement achieved by POLDIRAD on 21 July 1992 (Fig. 1). The quality-index field is based on radar reflectivity since this is the quantity mostly provided by radar systems. However, this quality-index scheme can be applied in the same way to reflectivity products that are based on radar power measurements such as precipitation estimation.

\section{b. Utilizing beam broadening and height of the first radar echo}

For measurements taken at far distance, the radar beam expands in horizontal and vertical directions.
Consequently, the probability rises that the radar beam is inhomogeneously filled by meteorological targets. Brightband correction becomes difficult when the radar beam extent is larger than the brightband thickness. Additionally, the height of the radar beam increases with range. This can lead to overshooting precipitation and errors when extrapolating data to the ground. Effects due to anomalous propagation of the radar beam intensify with increasing range from the radar yielding to a wrong spatial positioning of the precipitation areas and to ground clutter contamination. Table 2 lists several factors contributing to uncertainties and their trends with increasing range and beam elevation. One can assume that the accuracy of the reflectivity measurements decreases linearly with increasing distance from the radar (Fig. 3a). Therefore, $F_{\text {range }}$ is determined as

TABLE 2. Factors leading to uncertainties in the reflectivity and Doppler velocity measurements. Trends with increasing range and height of the beam elevations are outlined [adapted and modified from Yuter (2003)].

\begin{tabular}{llll}
\hline \hline & \multicolumn{1}{c}{ Factor } & $\begin{array}{l}\text { Trend of uncertainty with } \\
\text { increasing range }\end{array}$ & \multicolumn{1}{c}{$\begin{array}{c}\text { Trend of uncertainty with } \\
\text { increasing beam elevation }\end{array}$} \\
\hline Persistent bias & $\begin{array}{l}\text { Beam shielding } \\
\text { Resolution (e.g., for brightband } \\
\text { correction, detection of hail pockets) }\end{array}$ & $\begin{array}{l}\text { Increases with range } \\
\text { Decreases with range }\end{array}$ & Decreases with higher beam elevation \\
Intermittent bias & $\begin{array}{l}\text { Anomalous propagation } \\
\text { Attenuation }\end{array}$ & $\begin{array}{l}\text { Increases with range } \\
\text { Accumulates with range }\end{array}$ & Increases with smaller beam elevation \\
& $\begin{array}{l}\text { Inhomogeneous beam filling } \\
\text { Overshooting precipitation }\end{array}$ & $\begin{array}{l}\text { Increases with range } \\
\text { Increases with range }\end{array}$ & Increases with larger beam elevation \\
\hline
\end{tabular}




$$
F_{\text {range }}=\left\{\begin{array}{lll}
0 & \text { for } \quad r \geq r_{\max } \\
1 & \text { for } \quad r \leq r_{\min } \\
\frac{r_{\max }-r}{r_{\max }-r_{\min }} & \text { for } \quad r_{\min }<r<r_{\max },
\end{array}\right.
$$

with $r_{\max }$ and $r_{\min }$ being the maximum and minimum range, respectively, and $r$ being the distance between target and radar. Figure 4 illustrates the distribution of $F_{\text {range }}$ for a plan position indicator (PPI) ranging between 0.75 and $300 \mathrm{~km}$, which is the maximum spatial coverage achieved at 1953 UTC on 21 July 1992.

Maximum range should be set according to product and user requirements based on the maximum resolution volume size, $V_{\max }$, and the maximum height of the first radar echo, $H_{\text {max }}$, as

$$
\begin{aligned}
r_{\max , 1}= & \sqrt{\frac{8 V_{\max }}{\pi \Theta \Phi c \tau}}, \\
r_{\max , 2}= & -R^{\prime} \sin (\phi) \\
& +\sqrt{R^{\prime 2} \sin ^{2} \phi+R^{\prime 2}+\left(H_{\max }+R^{\prime}\right)^{2}},
\end{aligned}
$$

$$
r_{\max }=\min \left(r_{\max , 1}, r_{\max , 2}\right)
$$

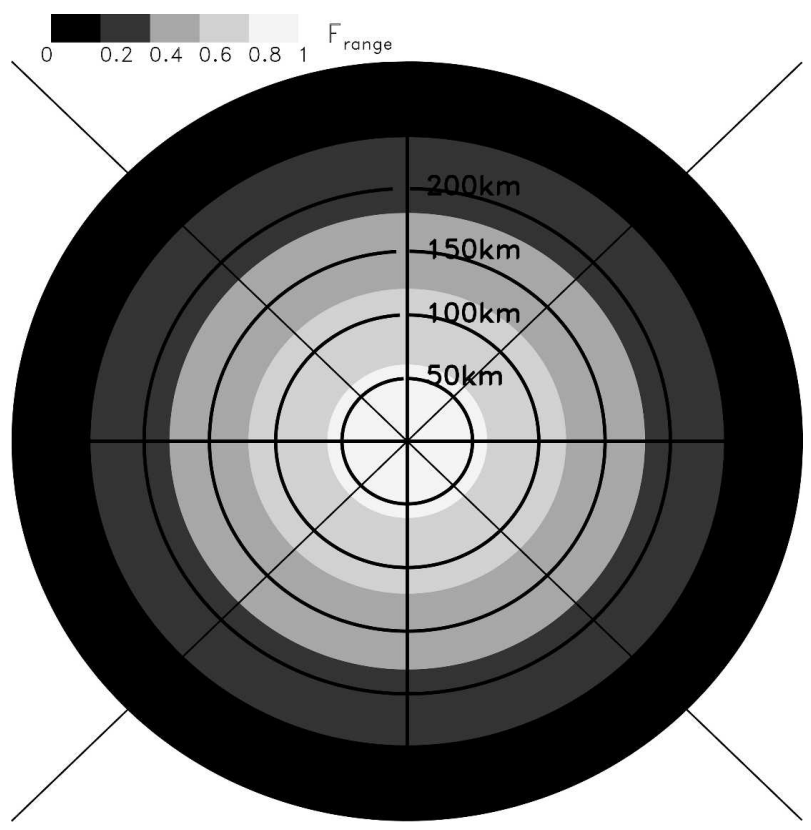

FIG. 4. Quality-index field $F_{\text {range }}$ representing the dependency of the size of the resolution volume and the height of the first radar echo on the distance from the radar. All observational data within a range between 0.75 and $300 \mathrm{~km}$ are included into the quality-index field in order to achieve a large spatial coverage. with $\Theta$ and $\Phi$ being the vertical and horizontal beamwidth; $\tau$ is denoted as pulse duration time; $c$ is the speed of light; $\phi$ is the elevation angle, and $R^{\prime}$ is $4 / 3$ of the earth's radius. The minimum value of $r_{\mathrm{max}, 1}$ and $r_{\mathrm{max}, 2}$ according to Eq. (5) is inserted into Eq. (2).

Figure 5 shows the increase in both resolution volume size and height of the first radar echo with increasing distance. On 21 July $1992 r_{\max }$ was set to $300 \mathrm{~km}$ yielding to a maximum volume size of $6.4 \mathrm{~km}^{3}$ and a height of the first radar echo of $10.5 \mathrm{~km}\left(\phi=1^{\circ}, \Theta=\right.$ $\left.\Phi=1^{\circ}, \tau=2 \mu \mathrm{s}\right)$.

As a result, the maximum range depends on the spatial resolution and coverage required. Table 3 lists minimum and maximum ranges for different applications. For nowcasting requiring a large spatial coverage, $r_{\max }$ should be chosen to be as large as possible. For rainrate estimations requiring high-resolution measurements close to the ground, the maximum range should not exceed $130 \mathrm{~km}$ yielding to a maximum resolution volume of $0.61 \mathrm{~km}^{3}$ and the first radar echo at $3.3-\mathrm{km}$ height. For data assimilation, however, $r_{\max }$ should be adjusted to the spatial resolution of the numerical model.

\section{c. Utilizing ground clutter contamination}

Ground clutter can totally or partially shield the transmitted radar beam and can contaminate directly the received signal due to a strong backscattering signal. Over the last few years great effort has been achieved by detecting and removing ground clutter using Doppler velocity information in signal processing (see, e.g., Lee et al. 1995; Hagen 1997; Joss et al. 1998; Seltmann 2000). Nevertheless, even an efficiently work-

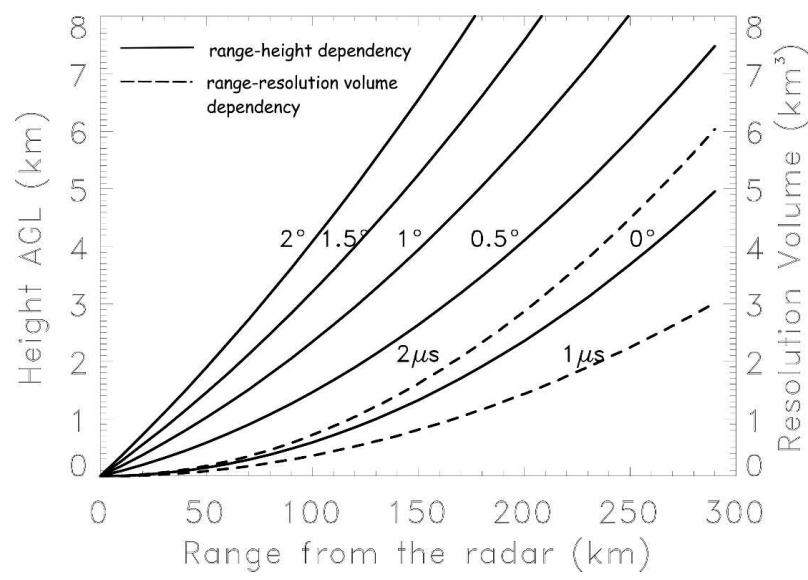

FIG. 5. Diagram illustrating the range-height (solid lines) and range-resolution volume dependency (dashed lines) for different elevation angles and pulse duration times, respectively. The horizontal and vertical beamwidth is assumed to be $1^{\circ}$. 
TABLE 3. Threshold limits for creating the quality-index fields according to the application and weather situation. Range limits indicated by the maximum and minimum distance from the radar, $r_{\min }$ and $r_{\max }$, are required for reflectivity, polarimetric parameters, and Doppler velocity. Lower and upper thresholds for attenuation by hydrometeors are indicated by $K_{\min }$ and $K_{\max }$, respectively. For polarimetric parameters cross-beam gradients limit ranging between $g_{\min }$ and $g_{\max }$, and limits for the differences between measured and estimated KDP $\left(e_{\min }\right.$ and $\left.e_{\max }\right)$ are required. To detect non-weather-related objects in the Doppler velocity field the deviation of the Doppler velocity measurement from applied fitting coefficient is denoted as $\varepsilon$. Note that some thresholds are based on empirical findings using a polarimetric C-band Doppler radar located in the Alpine foreland. Here $\Delta x$ and $\Delta y$ denote the horizontal resolution of a numerical weather prediction model.

\begin{tabular}{|c|c|c|c|c|c|c|c|c|c|}
\hline & $\begin{array}{r}r_{\min } \\
(\mathrm{km})\end{array}$ & $r_{\max }(\mathrm{km})$ & $\begin{array}{l}K_{\min } \\
(\mathrm{dB}) \\
\end{array}$ & $\begin{array}{l}K_{\max } \\
(\mathrm{dB})\end{array}$ & $\begin{array}{c}g_{\min } \\
\left(\mathrm{dB} \mathrm{deg}^{-1}\right)\end{array}$ & $\begin{array}{c}g_{\max } \\
\left(\mathrm{dB} \mathrm{deg}^{-1}\right)\end{array}$ & $\begin{array}{c}e_{\min } \\
\left(\operatorname{deg~km}^{-1}\right)\end{array}$ & $\begin{array}{c}e_{\max } \\
\left(\operatorname{deg~km}^{-1}\right)\end{array}$ & $\begin{array}{c}\varepsilon \\
\left(\mathrm{m} \mathrm{s}^{-1}\right)\end{array}$ \\
\hline \multicolumn{10}{|l|}{ Nowcasting } \\
\hline Stratiform & 0 & $r_{\max }$ & 1 & 5 & 0 & 15 & 0 & 0.5 & 4 \\
\hline Convective & 0 & $r_{\max }$ & 1 & 3 & 0 & 20 & 0 & 1.0 & 8 \\
\hline Hybrid & 0 & $r_{\max }$ & 1 & 4 & 0 & 20 & 0 & 1.0 & 8 \\
\hline \multicolumn{10}{|l|}{ Assimilation } \\
\hline Stratiform & 0 & $r_{\max } \sim \Delta x, \Delta y$ & 1 & 5 & 0 & 15 & 0 & 0.5 & 4 \\
\hline Convective & 0 & $r_{\max } \sim \Delta x, \Delta y$ & 1 & 3 & 0 & 20 & 0 & 1.0 & 8 \\
\hline Hybrid & 0 & $r_{\max } \sim \Delta x, \Delta y$ & 1 & 4 & 0 & 20 & 0 & 1.0 & 8 \\
\hline \multicolumn{10}{|c|}{ Rain-rate estimation } \\
\hline Stratiform & 0 & $80-130$ & 1 & 5 & 0 & 15 & 0 & 0.5 & 4 \\
\hline Convective & 0 & $80-130$ & 1 & 3 & 0 & 20 & 0 & 1.0 & 8 \\
\hline Hybrid & 0 & $80-130$ & 1 & 4 & 0 & 20 & 0 & 1.0 & 8 \\
\hline
\end{tabular}

ing Doppler velocity filter can incorrectly remove precipitation information especially for slowly moving or stationary precipitation and does not consider beamshielding effects.

In case of beam shielding, the reduced peak intensity propagates further, leading to a reduced backscattering signal as illustrated schematically in Fig. 6a. Furthermore, behind the target the received signal is assigned to a lower height because the main beam is shielded and the backscattering signal comes from the pulse edges (Fig. 6b).

The quality-index field $F_{\text {shield }}$ ranges between zero for a complete shielding of the transmitted beam (Fig. 6b) to one for no shielding (Fig. 6c) as schematically illustrated in Fig. 3b. For partial shielding the power gain pattern of the transmitted beam can be approximated as an angular weighting function as

$$
F_{\text {shield }}=0.5 \tanh \left(4 \ln (2)\left[\theta_{0}-\theta_{\mathrm{GL}}\right] \Theta\right)+0.5,
$$

with $\theta_{0}$ representing the elevation angle of the mainlobe axis and $\theta_{\mathrm{GL}}$ being the elevation angle of the ground clutter from the radar. The $3-\mathrm{dB}$ beamwidth is indicated as $\Theta$. When using Eq. (6), it is assumed that the ground clutter occurs as a horizontal line inside the area illuminated by the radar beam. A more precise characterization of mountain returns is illustrated by Delrieu et al. (1995). Here $F_{\text {shield }}$ is calculated for the respective range gate, while the following gates in radial outward direction are flagged according to the value of $F_{\text {shield }}$.

Figure 7 presents the horizontal distribution of $F_{\text {shield }}$ for a radial sampling range of $300 \mathrm{~km}$ around POLDIRAD. The calculation is based on the topography dataset measured by the European Remote Sensing Satellite-2 (ERS-2) satellite with a horizontal resolution

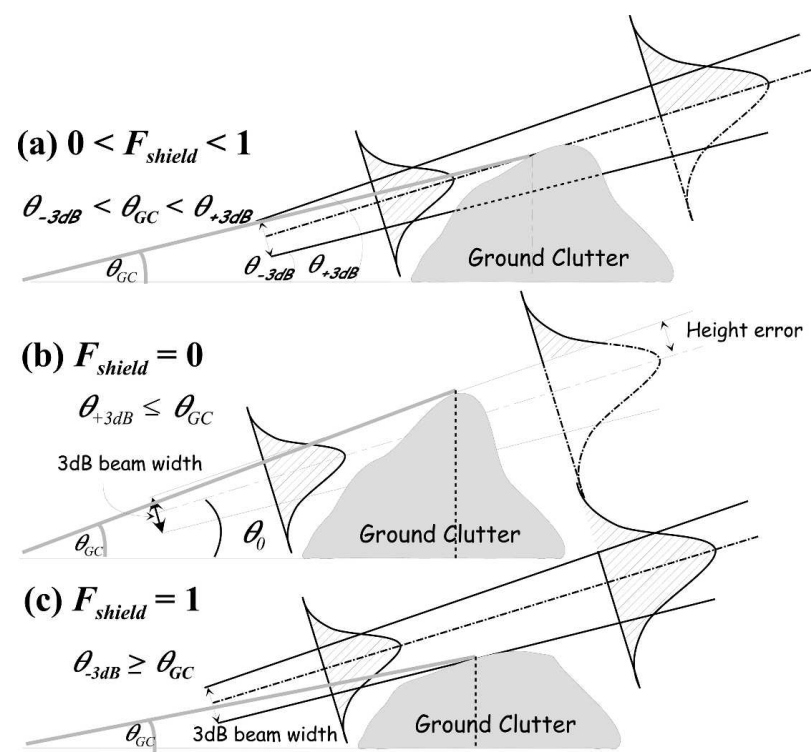

FIG. 6. Principle for estimating the loss of transmitted power with respect to the unobscured beam distinguishing between (a) partial shielding $\left(0<F_{\text {shield }}<1\right)$, (b) complete shielding $\left(F_{\text {shield }}=\right.$ $0)$, and (c) no shielding $\left(F_{\text {shield }}=1\right)$ of the $3-\mathrm{dB}$ radar beam. The 3 -dB beamwidth is indicated by $\theta_{-3 \mathrm{~dB}}$ and $\theta_{+3 \mathrm{~dB}}$. The elevation angle of the mainlobe axis is denoted as $\theta_{0}$. The angle spanning between ground level and clutter height is denoted as $\theta_{\mathrm{GC}}$. The elevation angles are related to the radar site. The radiation pattern of the transmitted pulse is pictured having a Gaussian distribution. 


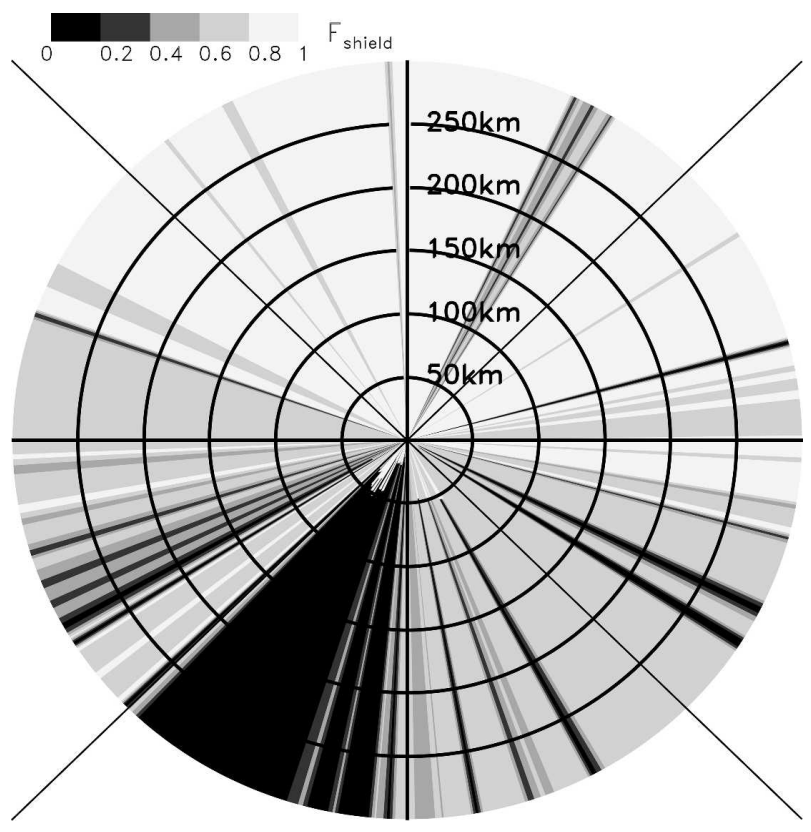

FIG. 7. Quality-index field $F_{\text {shield }}$ presenting the amount of beam shielding for the POLDIRAD antenna at an elevation angle of $0.7^{\circ}$. No shielding is indicated by $F_{\text {shield }}=1$, while total beam blockage is assigned by $F_{\text {shield }}=0$. Calculations were based on the topography dataset measured by the ERS-2 satellite.

of about $250 \mathrm{~m}$ and a vertical one of $1 \mathrm{~m}$. The data are averaged and interpolated onto a spherical coordinate system with an angular resolution of $1^{\circ}$ and a radial resolution of $250 \mathrm{~m}$. Figure 7 illustrates beam shielding for an elevation limit ranging between $0.2^{\circ}$ and $1.2^{\circ}$ (POLDIRAD configuration for 21 July 1992). Based on the ground clutter map, strong or complete shielding of the radar beam is expected within the first $50-\mathrm{km}$ range southeast, south, and southwest of the radar. Partial shielding occurs mainly east, southeast, southsouthwest, and west of the radar. The ground clutter contamination is also visible as high-reflectivity returns in optical clear air shown in Fig. 1. While ground clutter contamination south and southeast of POLDIRAD is clearly visible in the reflectivity field (Fig. 1), ground clutter returns southwest of the radar are embedded in precipitation.

\section{d. Utilizing attenuation by hydrometeors}

Attenuation of electromagnetic energy by hydrometeors results from both absorption and scattering. The amount of absorption by water or ice, however, depends on the transmitted wavelength $(\lambda)$. It mainly occurs at radars operating at $4 \mathrm{GHz}$ ( $\mathrm{C}$ band) or higher frequencies. Attenuation accumulates behind large reflectivity values in radial direction such as behind convective storms or the bright band. An example of strong attenuation of electromagnetic energy by precipitation at $\lambda=5.5 \mathrm{~cm}$ ( $\mathrm{C}$ band) is given in Fig. 1. Behind the strong reflectivity values $(\sim 40 \mathrm{dBZ})$ located between 25 and $50 \mathrm{~km}$ west of POLDIRAD oriented in northsouth direction, the reflectivity factor is reduced to 10 $20 \mathrm{~dB}$. The objective of this quality-index field is to quantify the amount of contamination due to attenuation.

Precipitating particles consisting of raindrops are assumed to be located below the $0^{\circ} \mathrm{C}$ isotherm [hereafter referred to as freezing level (FL)]. One-way pathlength attenuation by rain $\left(K_{r}\right)$ is calculated for a C-band radar according to the empirical formula by Doviak and Zrnic (1992) for temperatures between $0^{\circ}$ and $40^{\circ} \mathrm{C}$ as

$$
K_{r}=2 \times 10^{-5} \exp (0.17 Z) .
$$

Above the freezing level, we assume that the electromagnetic energy is solely attenuated by snow. Attenuation by other hydrometeors like graupel and hail is hard to quantify since it strongly depends on the thickness of the coating water shell. One-way pathlength attenuation by snow $\left(K_{s}\right)$ is calculated for temperatures around $0^{\circ} \mathrm{C}$ following Battan (1973, p. 74) as

$$
K_{s}=3.5 \times 10^{-2}\left(R^{2} / \lambda^{4}\right)+2.2 \times 10^{-3}(R / \lambda) .
$$

To calculate rain rate $(R)$ we choose the $Z-R$ relation $\left(Z=256 R^{1.42}\right)$, which is used by the German Weather Service (Aniol et al. 1980).

Figure 8 a illustrates two-way pathlength attenuation by rain and snow based on the reflectivity field measured at 1953 UTC on 21 July 1992 shown in Fig. 1. For that purpose Eqs. (7) and (8) are integrated along the radial path. Based on a radiosounding launched at 1200 UTC, the height of the freezing level was located at about $3 \mathrm{~km}$. The freezing levels can be determined alternatively from the location of the bright band in the radar reflectivity or a sounding derived from numerical weather prediction model output. For an elevation angle of $0.7^{\circ}$, measurements beyond a range larger than $123.3 \mathrm{~km}$ from POLDIRAD are located above the freezing level. In this area, the electromagnetic energy is attenuated by snow [Eq. (8)]. Within 123.3-km range, pathlength attenuation by raindrops is assumed [Eq. (7)]. A discrepancy between the relatively low attenuation in Fig. $8 \mathrm{a}(\sim 5 \mathrm{~dB})$ and the relatively high decrease in reflectivity in Fig. $1(\sim 20 \mathrm{dBZ})$ occurs behind the main reflectivity core west of the radar. This area consists probably of a mixture of ice particles, melting hail, and rain, while solely attenuation by rain is assumed [Eq. (7)]. Attenuation caused by the bright band within stratiform precipitation that also contains a mixture of rain and melting particles has been investigated by Bellon et al. (1997) using X-band radar and a UHF verti- 
(a)

(b)

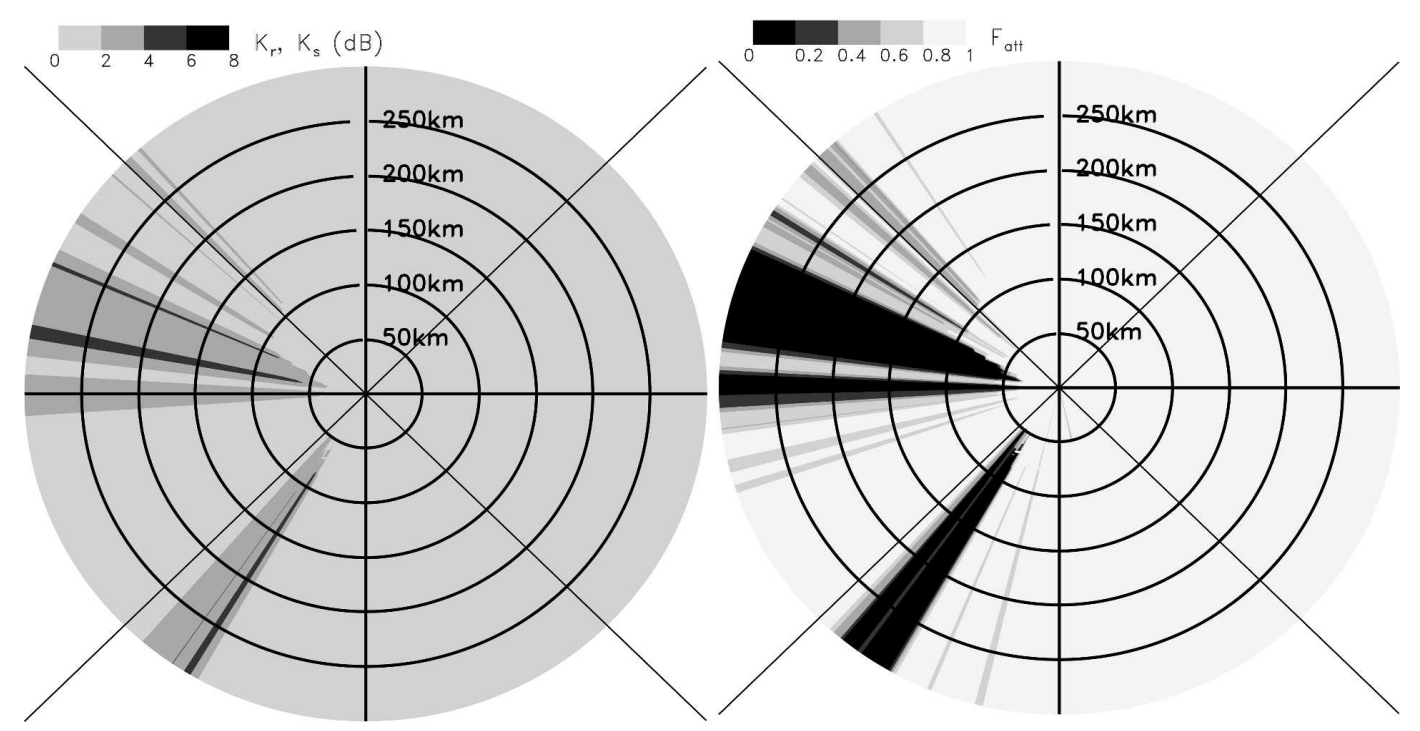

FIG. 8. (a) Two-way pathlength attenuation by rain $\left(K_{r}\right)$ and snow $\left(K_{s}\right)$ and (b) the respective quality-index field $F_{\text {att }}$ for the reflectivity field measured by POLDIRAD on 21 Jul 1992 (Fig. 1). (a) Attenuation by rain is assumed below the freezing level, while electromagnetic energy is expected to be attenuated by snow above the freezing level, which is located at $3 \mathrm{~km}$ MSL corresponding to a range of $123.3 \mathrm{~km}$ from the radar.

cally pointing radar. Brightband attenuation 3-5 times larger than the rain equivalent was observed. Also, in Fig. 1 reflectivity is displayed as plan position indicator; that is, the radar beam at $150 \mathrm{~km}$ is located about 2.4 $\mathrm{km}$ higher compared to the $50-\mathrm{km}$ range. Areas of lower reflectivity are intersected at farther ranges.

The quality-index field $F_{\text {att }}$ considering two-way pathlength attenuation is determined according to Fig. $3 \mathrm{c}$ as

$$
F_{\text {att }}= \begin{cases}1 & \text { for } K_{r, s}<K_{\min } \\ 0 & \text { for } K_{r, s}>K_{\max } \\ \frac{K_{\max }-K_{r, s}}{K_{\max }-K_{\min }} & \text { else, }\end{cases}
$$

with $K_{\max }$ and $K_{\min }$ being the upper and lower threshold for attenuation, respectively. The distribution of $F_{\text {att }}$ is illustrated in Fig. $8 \mathrm{~b}$ based on the amount of attenuation displayed in Fig. 8a. The maximum attenuation rate $K_{\max }$ is empirically chosen to be $3 \mathrm{~dB}$, while the minimum is set to $1 \mathrm{~dB}$.

Attenuation effects are very critical for rain-rate estimations. Figure 9 portrays the differences in rain-rate estimation when using a reflectivity value that is 3-5 $\mathrm{dBZ}$ lower than the true value. When a reflectivity value of $35 \mathrm{dBZ}$ instead of $40 \mathrm{dBZ}$ is measured, which is equivalent to an attenuation of $5 \mathrm{~dB}$, the error in rain-rate estimation is about $7 \mathrm{~mm} \mathrm{~h}^{-1}$. This value increases to $25 \mathrm{~mm} \mathrm{~h}^{-1}$ when a reflectivity value of 47
$\mathrm{dB} Z$ instead of $50 \mathrm{dBZ}$ (3-dB attenuation) is used. The threshold for the maximum attenuation $K_{\max }$ is set to 5 $\mathrm{dB} Z$ for stratiform precipitation, which consists mainly of moderate rain and snow particles with typical reflectivity values less than $40 \mathrm{dBZ}$. Within convective precipitation, $K_{\max }$ is reduced to $3 \mathrm{dBZ}$ since the precipitation consists of a mixture of snow, graupel, hail, and larger raindrops $(>5 \mathrm{~mm})$. These thresholds can be applied to all applications as listed in Table 3.

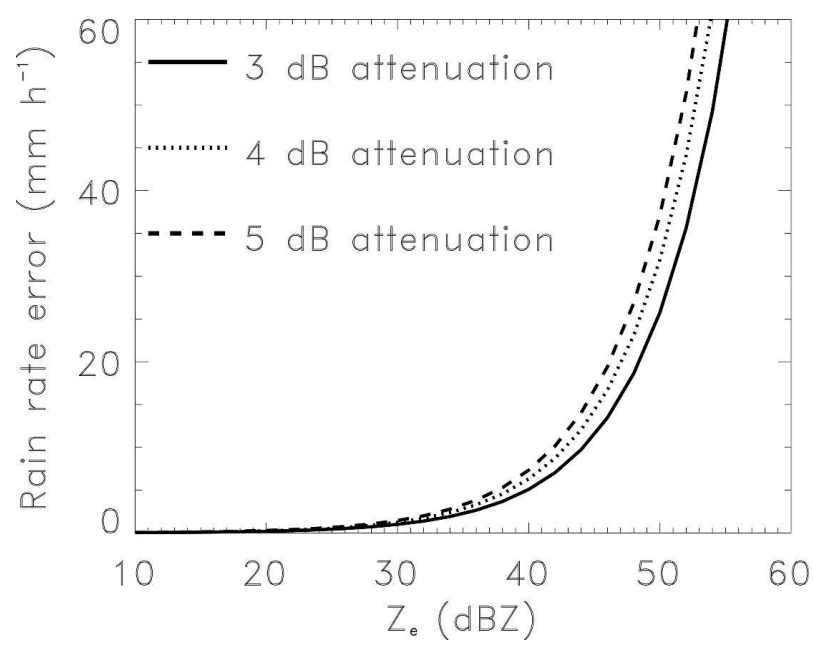

FIG. 9. Diagram illustrating the bias in rain-rate estimation when the reflectivity shown along the abscissa is reduced by 3,4 , or $5 \mathrm{~dB}$ due to attenuation effects. 


\section{e. Utilizing vertical reflectivity profile}

The vertical profile of reflectivity is highly variable in time and space owing to different growth effects (e.g., coagulation, distribution, condensation, evaporation), change of phase of water (e.g., ice, liquid, melting snow), fall speed, and the dependence of $Z_{e}$ on the sixth power of the hydrometeor size. To overcome this variability, a simple approach is suggested for a qualityindex field. Reflectivity values within the layer close to the $0^{\circ}$ isotherm (referred to as melting layer or bright band) are overdetermined since it consists mainly of water-coated non-Rayleigh scatterers. This area is flagged with a zero quality index. The melting layer is usually located between $200 \mathrm{~m}$ above the FL to $500 \mathrm{~m}$ below it (Doviak and Zrnic 1992).

The principle for determining the variation of the vertical reflectivity field is illustrated in Fig. 10. Resolution volumes located entirely below the melting layer are assumed to be within rain indicated as $F_{\mathrm{vpr}}=1$. Above the melting layer, snow, hail, or graupel are present; the representativeness is marked as 0.5. Resolution volumes intersecting the upper and lower boundary of the melting layer are weighted according to its intersecting area. The formula is given as

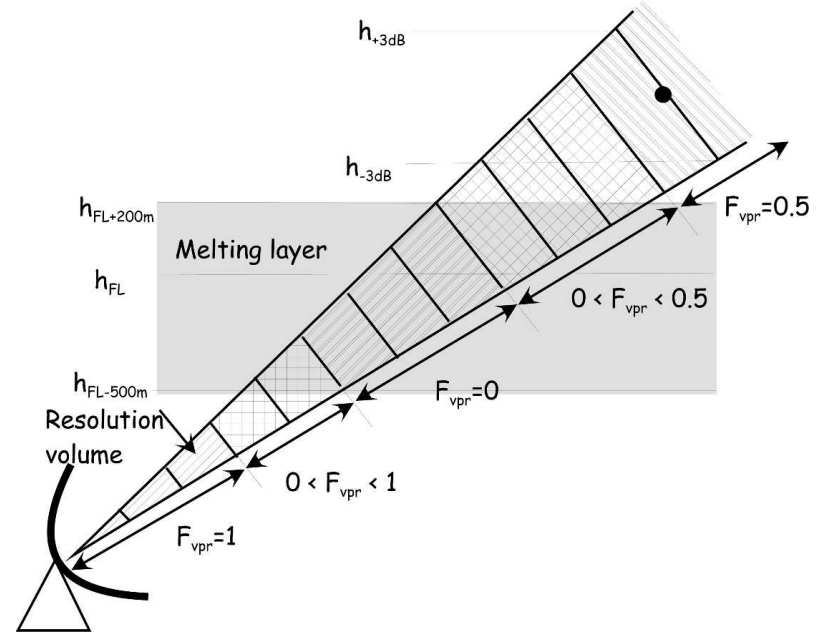

FIG. 10. Principle for estimating the variation of the vertical reflectivity field. Range resolution volumes located entirely below the melting layer (single-dashed area) are classified as $F_{\mathrm{vpr}}=1$. Range resolution volumes located within the melting layer (double-dashed area) are encoded as $F_{\mathrm{vpr}}=0$. All measurements above the melting layer are encoded as $F_{\mathrm{vpr}}=0.5$ (double-dashed area). Range volumes that encounter the lower and upper boundary of the melting layer (cross-hatched areas) are classified according to Eq. (10). Melting layer is located between $500 \mathrm{~m}$ below the $0^{\circ}$ isotherm (denoted as hFL) and $200 \mathrm{~m}$ above it.

$$
F_{\mathrm{vpr}}=\left\{\begin{array}{lll}
\frac{h_{+3 \mathrm{~dB}}-h_{\mathrm{FL}+200 \mathrm{~m}}}{2\left(h_{+3 \mathrm{~dB}}-h_{-3 \mathrm{~dB}}\right)} & \text { for } h_{-3 \mathrm{~dB}}<h_{\mathrm{FL}+200 \mathrm{~m}} \text { and } h_{+3 \mathrm{~dB}}>h_{\mathrm{FL}+200 \mathrm{~m}} \text { and } h_{-3 \mathrm{~dB}}>h_{\mathrm{FL}-500 \mathrm{~m}} \\
0.5 & \text { for } h_{-3 \mathrm{~dB}} \geq h_{\mathrm{FL}+200 \mathrm{~m}} \\
1 & \text { for } h_{+3 \mathrm{~dB}} \leq h_{\mathrm{FL}-500 \mathrm{~m}} \\
0 & \text { for } h_{-3 \mathrm{~dB}}>h_{\mathrm{FL}-500 \mathrm{~m}} \text { and } h_{+3 \mathrm{~dB}}<h_{\mathrm{FL}+200 \mathrm{~m}} \\
\frac{h_{-3 \mathrm{~dB}}-h_{\mathrm{FL}-500 \mathrm{~m}}}{h_{-3 \mathrm{~dB}}-h_{+3 \mathrm{~dB}}} & \text { for } h_{-3 \mathrm{~dB}}<h_{\mathrm{FL}-500 \mathrm{~m}} \text { and } h_{+3 \mathrm{~dB}}>h_{\mathrm{FL}-500 \mathrm{~m}}
\end{array}\right.
$$

with $h_{-3 \mathrm{~dB}}$ and $h_{+3 \mathrm{~dB}}$ being the lower and upper height of the $3-\mathrm{dB}$ radar beam, and $h_{\mathrm{FL}-500 \mathrm{~m}}$ and $h_{\mathrm{FL}+200 \mathrm{~m}}$ the upper and lower height of the melting layer, respectively.

Figure 11 illustrates the distribution of $F_{\mathrm{vpr}}$ at 1953 UTC on 21 July 1992. According to the radiosounding at 1200 UTC, the melting layer ranges between a height of 2.5 and $3.2 \mathrm{~km}$ MSL corresponding to a radial distance of 103.7 and $130.6 \mathrm{~km}$ from POLDIRAD.

\section{f. Average quality-index field for reflectivity}

All separately calculated quality-index fields are now averaged according to Eq. (1). The reflectivity observed on 21 July 1992 and the average quality-index field $\overline{F_{Z_{e}}}$ are presented in Fig. 12. The impact of each error source on the overall quality is treated equally setting all weight to one. Gross errors such as ground clutter contamination southeast of POLDIRAD have been removed by basic quality algorithms.

Radar reflectivities with high quality are observed close to the radar at a range of $50 \mathrm{~km}$ and northwest of the radar where no obvious ground clutter and attenuation contamination was discovered. High uncertainties of the reflectivity measurements $\left(\overline{F_{Z_{e}}}<0.2\right)$ were determined in areas of combined beam shielding and attenuation occurring southwest of the radar and areas of strong attenuation west-northwest of the radar.

Weighting factors need to be chosen according to weather situation and application as demonstrated in Table 1. Influence of range resolution and beam shielding on $\overline{F_{Z_{e}}}$ are independent from the weather situation. Weighing factors for $F_{\text {range }}$ are set to one, since the uncertainties in the reflectivity mapping increase with increasing range (Table 2). The weighting factor for 


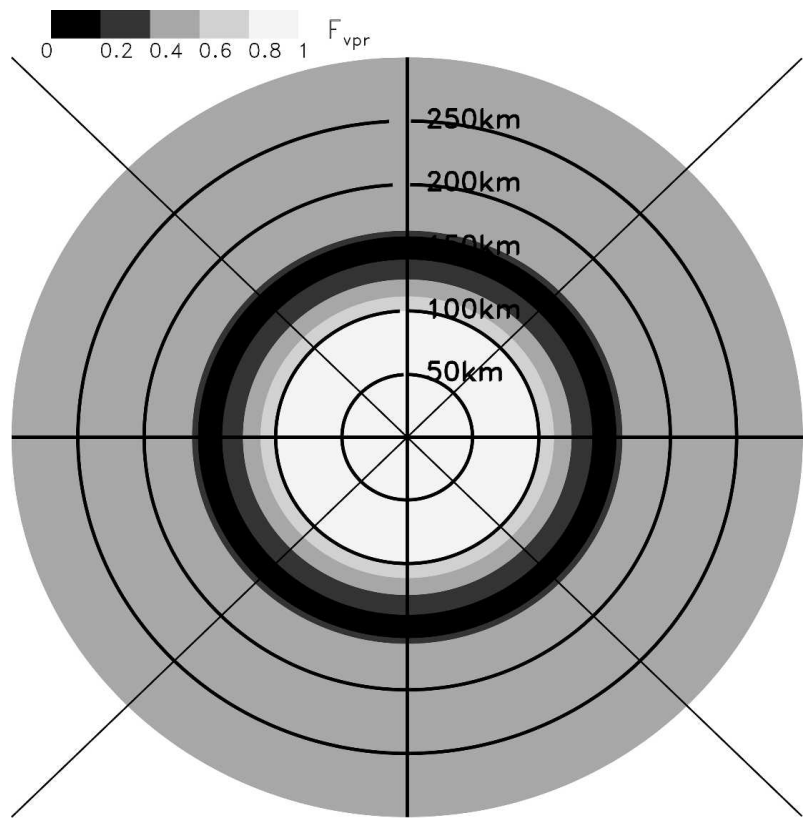

FIG. 11. Quality-index field illustrating the representativeness of the vertical reflectivity profile $F_{\mathrm{vpr}}$ for the $21 \mathrm{Jul} 1992$ case.

ground clutter contamination ranges between 0.5 and 1.0 for mountainous terrain. The impact of attenuation on $\overline{F_{Z_{e}}}$ varies according to the weather situation setting this value to one during convective precipitation. The variable vertical profile of the radar reflectivity has the highest impact on the rain-rate estimation setting $W_{\mathrm{vpr}}$ to one and lesser impact on assimilation and nowcasting.

\section{Quality-index scheme for polarimetric radar products}

\section{a. Methodology}

Although polarimetric radar products have not been derived operationally yet, future trends toward opera- tionally working radars with polarimetric diversity capabilities can be seen (Zrnic 1996; Parent du Châtelet et al. 2005). Polarimetric radar measurements have improved quantitative precipitation estimation especially in terms of reducing the uncertainty caused by the unknown $Z-R$ relation. Nevertheless, as shown by Seliga and Bringi (1976) and Richter and Hagen (1997), polarimetric quantities are required with high accuracy, otherwise a large error in rainfall-rate retrieval will occur.

The quality-index field for polarimetric radar products can be used either for calculating rain rates or for using directly polarimetric quantities like the linear depolarization ratio (LDR), differential reflectivity ratio (ZDR), and differential propagation phase (KDP). The following parameters have to be considered for calculating a quality-index field for polarimetric radar products:

1) beam broadening and height of the first radar echo (denoted as $F_{\text {range }}$ ),

2) partial or complete beam shielding due to ground clutter (denoted as $F_{\text {shield }}$ ),

3) attenuation of electromagnetic energy by hydrometeors (denoted as $F_{\text {att }}$ ),

4) amount of homogeneous beam filling (denoted as $\left.F_{\text {bea }}\right)$,

5) rain or no-rain discrimination (denoted as $F_{\text {rain }}$ ),

6) consistency check between $Z_{e}$, ZDR, and KDP (denoted as $\left.F_{\text {con }}\right)$.

It can be assumed that $F_{\text {range }}$ and $F_{\text {shield }}$ are independent from the evolution of radar echoes, and therefore are calculated only once for a given scan strategy according to sections $3 \mathrm{~b}$ and $3 \mathrm{c}$. Qualityindex fields $F_{\text {att }}, F_{\text {bea }}, F_{\text {rain }}$, and $F_{\text {con }}$, which include the measured variables, are calculated for each radar scan.

The averaged quality-index fields for polarimetric radar products $\overline{F_{P}}$ are computed as

$$
\overline{F_{P}}=\left\{\begin{array}{l}
0 \text { for } F_{\text {att }}=0 \text { or } F_{\text {shield }}=0 \\
0 \text { for } F_{\text {rain }}=0 \text { when } W_{\text {rain }} \neq 0 \quad \text { and } \quad W_{\text {con }} \neq 0 \\
1 / C_{P}\left(W_{\text {range }} F_{\text {range }}+W_{\text {shield }} F_{\text {shield }}+W_{\text {att }} F_{\text {att }}+W_{\text {bea }} F_{E}+W_{\text {rain }} F_{\text {rain }}+W_{\text {con }} F_{\text {con }}\right) \text { else }
\end{array}\right.
$$

where

$$
C_{P}=W_{\text {range }}+W_{\text {shield }}+W_{\text {att }}+W_{\text {bea }}+W_{\text {rain }}+W_{\text {con }} \text {, }
$$

with $W_{\text {range }}, W_{\text {shield }}, W_{\text {att }}, W_{\text {bea }}, W_{\text {rain }}$, and $W_{\text {con }}$ being the respective weights. Table 1 gives an overview of weighting factor ranges, which will be discussed in more detail in the following sections.

In case of strong attenuation $\left(F_{\text {att }}=0\right)$ or ground clutter contamination $\left(F_{\text {shield }}=0\right), \overline{F_{P}}$ is set to zero. Uncertainty for rain-rate estimation within areas other than rain becomes very high. Therefore, only resolution volumes filled mainly with rain are considered for this application $\left(W_{\text {rain }} \neq 0, W_{\text {con }} \neq 0\right)$, otherwise $F_{\text {rain }}$ is set to zero. The computation of the quality-index fields is illustrated in Figs. 3a,b and Fig. 13.

The determination of the quality-index field for po- 
(a)

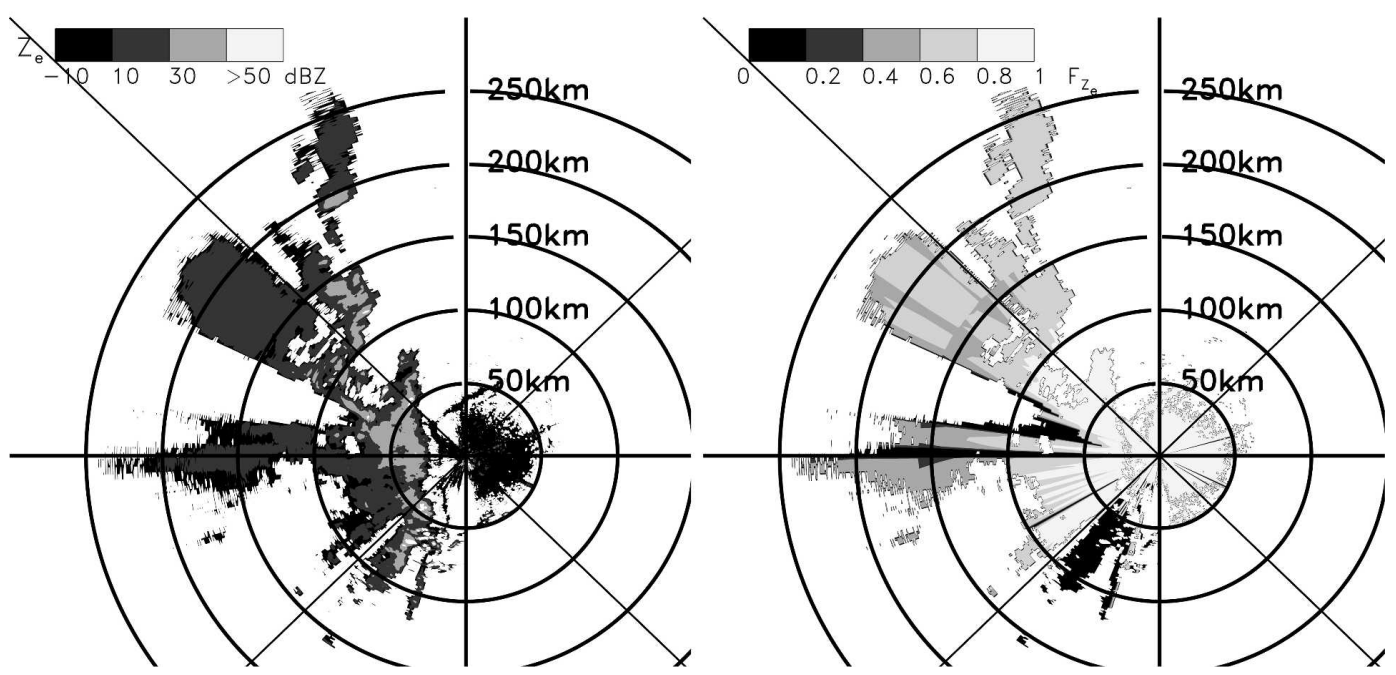

FIG. 12. (a) Reflectivity factor field $\left(Z_{e}\right)$ as presented in Fig. 1, but gross errors (e.g., ground clutter) have been filtered by basic quality algorithms. (b) Average quality control field for reflectivity $\left(\bar{F}_{Z_{e}}\right)$ in (a). The impact of each error source is treated equally by setting all weights to one.

larimetric parameters will be exemplified using radar measurement achieved by POLDIRAD at 1520 UTC on 26 June 1997. The reflectivity field using horizontally transmitted and received polarization at $1^{\circ}$ eleva-

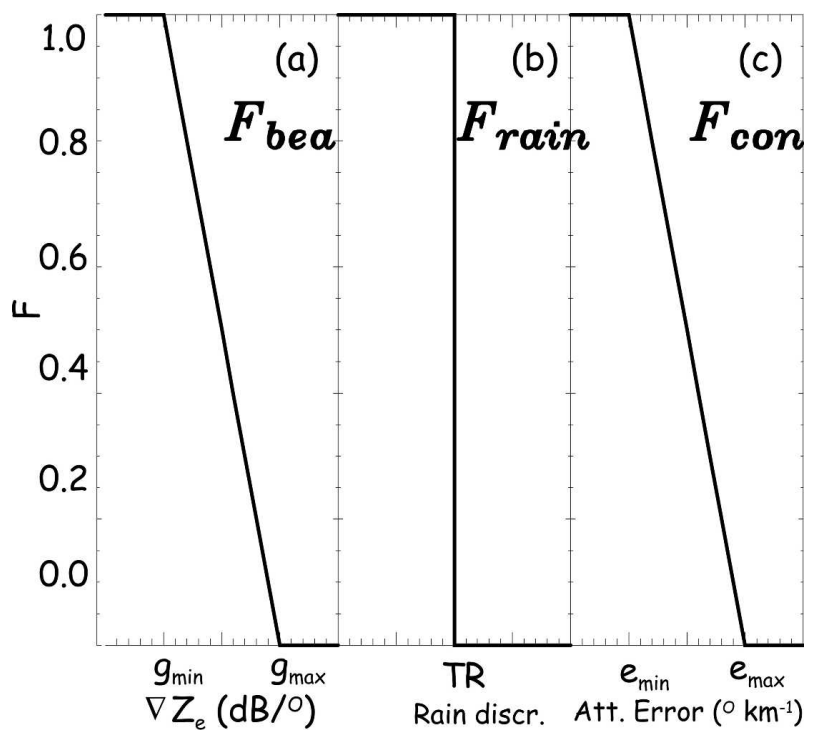

FIG. 13. Computation of the quality-index fields for polarimetric radar products based on (a) the influence of homogeneous beam filling $F_{\text {bea }}$, (b) the discrimination between rain and no rain $F_{\text {rain }}$, and (c) the consistency check $F_{\text {con }}$. The minimum and maximum threshold for the reflectivity gradient and the relative error for attenuation are denoted as $g_{\min }, g_{\max }$ and $e_{\min }, e_{\max }$, respectively. The thresholds for the rain and no rain discrimination, indicated as TR, are $T>0^{\circ} \mathrm{C}$ and $\mathrm{LDR}<-35 \mathrm{~dB}$. tion is presented in Fig. 14. With stratiform precipitation and embedded convection, this case is considered as having hybrid character.

\section{b. Utilizing beam broadening and first radar echo, ground clutter contamination, and attenuation}

The quality-index field identifying beam broadening, contamination due to ground clutter, and attenuation by hydrometeors can be applied for the same reasons and in the same way to polarimetric data as for reflectivity demonstrated in sections $3 \mathrm{~b}-\mathrm{d}$.

Linear depolarization ratio (LDR) is an excellent measure for ground clutter contamination and supplement clutter filters as shown by Hagen (1997). Unfortunately, most operational weather radars will derive polarimetric quantities without expensive polarization switches using simultaneous transmission and reception of horizontal and vertical polarization. As a consequence, LDR can only be retrieved by running a separate scan where only horizontal polarization will be transmitted. As an alternative to those time-consuming measurements, ZDR in combination with Doppler velocity can be used to identify ground clutter contamination (Giuli et al. 1991). However, if $Z_{e}$ or ZDR measurements are contaminated by ground clutter returns, the rain rate will be overestimated. Furthermore, Illingworth (2003) investigated that KDP can be heavily contaminated by ground clutter even when only the sidelobes hit the ground. Beam shielding affects mainly reflectivity measurements like ZDR and has less impact 


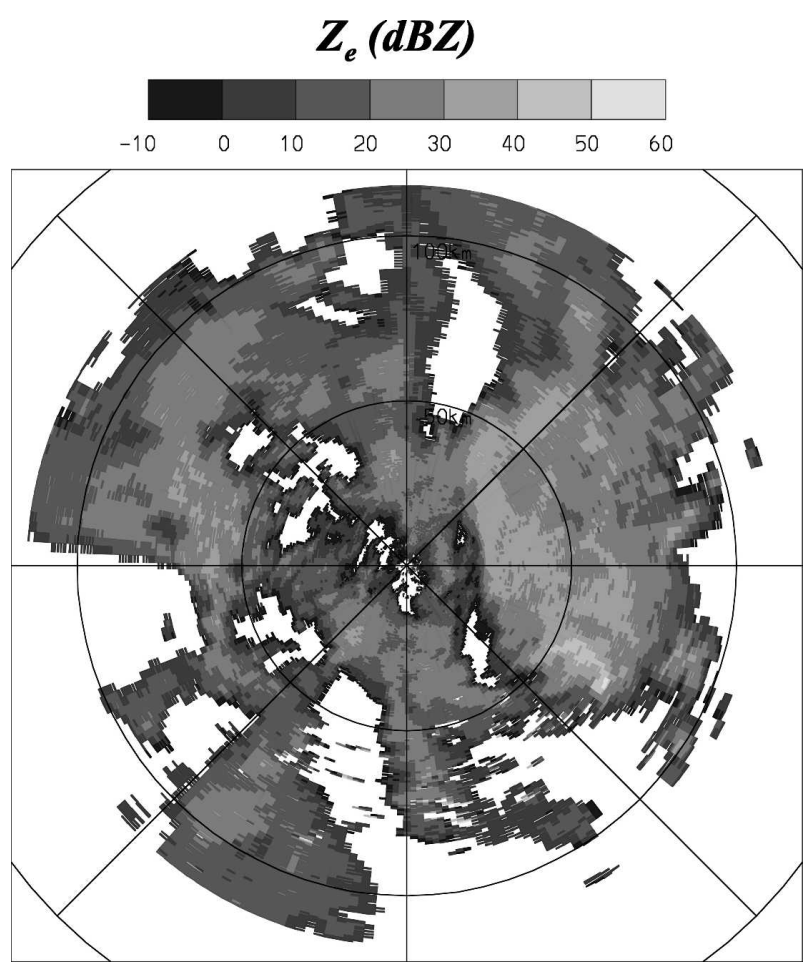

FIG. 14. PPI of the reflectivity factor field at $1^{\circ}$ elevation measured by POLDIRAD (located in the center) with transmitting and receiving horizontal polarization at 1520 UTC on 26 Jun 1997. Grayscale for reflectivity is shown at top. Range rings are plotted every $50 \mathrm{~km}$.

on the phase measurements. Nevertheless, signals are assigned to a lower height when shielding occurs as illustrated in Fig. 6b.

Attenuation of electromagnetic energy by hydrometeors affecting measurements is mainly observed at radars operating at $4 \mathrm{GHz}$ ( $\mathrm{C}$ band) or higher frequencies. In the presence of nonspherical particles, horizontally and vertically polarized waves are attenuated differently, resulting in a differential attenuation of ZDR (e.g., Gorgucci et al. 1998; Torlaschi and Zawadzki 2003). In rain, for instance, ZDR normally ranges between 0 and $3 \mathrm{~dB}$, but reduces due to differential attenuation and even becomes negative with intense rain. Attenuation affects only reflectivity measurements like $Z_{e}$ and ZDR; the differential phase measurements (KDP) are not affected by attenuation and therefore can be used to correct reflectivity [for more details see Gorgucci et al. (1998) or section 4e].

\section{c. Utilizing cross-beam gradients}

Homogeneously filled sample volumes without crossbeam reflectivity gradients are necessary in order to measure polarimetric variables like ZDR or KDP with high precision. Slight mismatch of the beam shape produces enormous errors in the presence of cross-beam reflectivity gradients (Chandrasekar and Keeler 1993). In addition high-reflectivity gradients yield to negative KDP (Ryzhkov and Zrnic 1998) - a value that is not expected for any kind of hydrometeors. Since both ZDR and KDP are reflectivity-weighted quantities, gradients of the horizontally polarized reflectivity are used to define $F_{\text {bea }}$. It ranges between zero for high horizontal and vertical gradients perpendicular to the transmitted radar beam and one for low-reflectivity gradients as

$$
F_{\text {bea }}= \begin{cases}1 & \text { for } g<g_{\min } \\ 0 & \text { for } g>g_{\max } \\ \frac{g_{\max }-g}{g_{\max }-g_{\min }} & \text { else }\end{cases}
$$

where

$$
g=\left|Z_{e}^{y 2}-Z_{e}^{y 1}\right|+\left|Z_{e}^{x 1}-Z_{e}^{x 2}\right|,
$$

with $Z_{e}^{y 2}, Z_{e}^{y 1}, Z_{e}^{x 1}$, and $Z_{e}^{x 2}$ being horizontally polarized reflectivity values of the range bins located above $(y 2)$, below $(y 1)$, left $(x 1)$, and right $(x 2)$ of the central pixel. The thresholds for minimum and maximum reflectivity gradients are denoted as $g_{\min }$ and $g_{\max }$, respectively.

Figure 15 illustrates the quality-index field $F_{\text {bea }}$ for the polarimetric radar measurements taken at 1520 UTC on 26 June 1997. Low values of $F_{\text {bea }}$ are observed along the edges of the precipitation cells and when reflectivity is contaminated by ground clutter, for instance, south of the radar; $F_{\text {bea }}$ also decreases when precipitation evolves and is advected with time between the elevation scans. This was observed on 26 June 1997 at an azimuth of $70^{\circ}$ and a range of $25 \mathrm{~km}$. The threshold $g_{\min }$ and $g_{\max }$ were set to $0 \mathrm{~dB} \mathrm{deg}^{-1}$ and $20 \mathrm{~dB}$ $\mathrm{deg}^{-1}$, respectively.

Not much experience has been collected with the effects of cross-beam gradients. It is unknown how far this effect will influence operational polarimetric measurements. Table 3 lists thresholds of $g_{\min }$ and $g_{\max }$ for different applications and weather situations. Generally, the maximum threshold should be higher than gradients observed along the edge of the bright band or convective cells. For convective weather situation $g_{\text {max }}$ should be set to about $20 \mathrm{~dB} \mathrm{deg}^{-1}$, while for stratiform precipitation $g_{\max }$ is set to $15 \mathrm{~dB} \mathrm{deg}{ }^{-1}$. At the same time, it should be smaller than the gradient of the antenna's power pattern between the main beam and the secondary lobe.

\section{d. Utilizing rain or no-rain discrimination}

Polarization diversity allows for the discrimination of the various types of precipitation particles (Höller et al. 


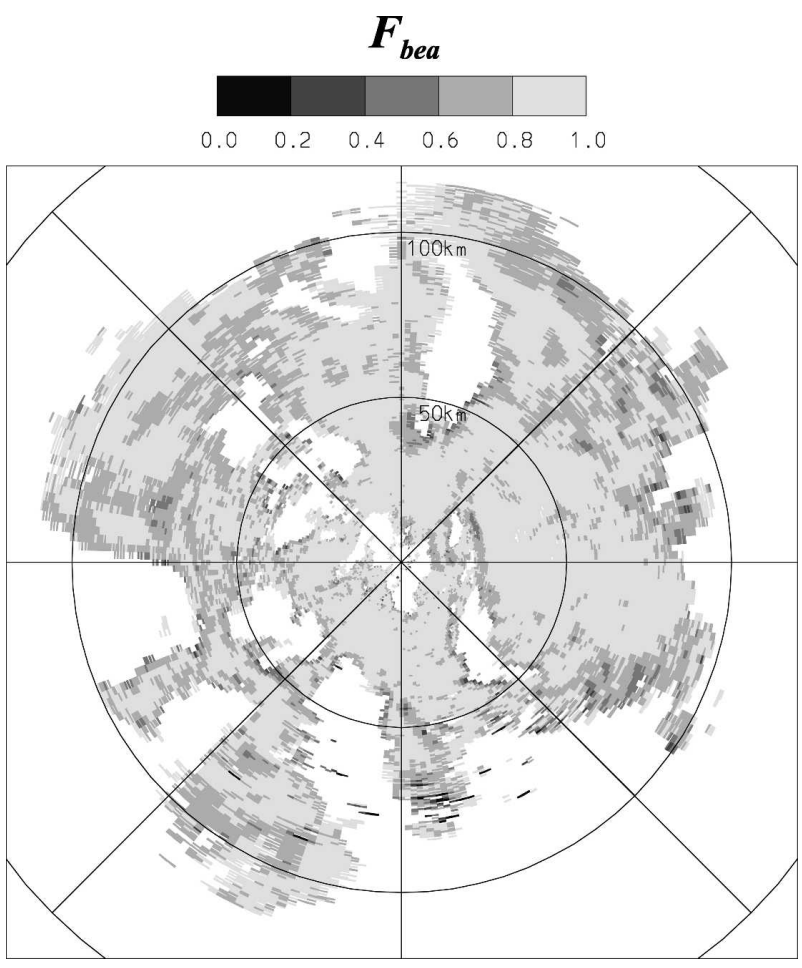

FIG. 15. Quality-index field $F_{\text {bea }}$ illustrating the amount of homogeneous beam filling by calculating the vertical and horizontal cross-beam reflectivity gradients. Calculations are based on the reflectivity field illustrated in Fig. 14.

1994; Vivekanandan et al. 1999). A quality-index field $F_{\text {rain }}$ is introduced in order to estimate polarimetric rainfall rate solely within regions dominated by raindrops.

Based on the classification introduced by Höller et al. (1994), the presence of rain $\left(F_{\text {rain }}=1\right)$ can be assumed when both the air temperature is above $0^{\circ} \mathrm{C}$ and LDR is below $-35 \mathrm{~dB}$, or when $\mathrm{LDR}$ ranges between -35 and $-25 \mathrm{~dB}$ and ZDR is above $1 \mathrm{~dB}$. Measurements indicating hydrometeors other than rain are denoted as $F_{\text {rain }}=0$ as schematically indicated in Fig. $13 \mathrm{~b} ; F_{\text {rain }}$ can be defined in a similar way using other classification schemes like the fuzzy logic scheme introduced by Vivekanandan et al. (1999).

Figure 16 shows the quality-index field $F_{\text {rain }}$ for the measurements obtained at 1520 UTC on 26 June 1997. Based on the radiosounding launched at 1200 UTC at Munich-Oberschleissheim located about $27 \mathrm{~km}$ northeast of the radar, the $0^{\circ}$ isotherm was located at about $1.8 \mathrm{~km}$ above the radar. As a result, hydrometeors observed beyond the $80-\mathrm{km}$ range are considered to include an ice phase. Ground clutter close to the radar and south of the radar are identified correctly as no rain by the algorithm. The areas with $F_{\text {rain }}=0$ to the west and east of the radar were identified as melting graupel

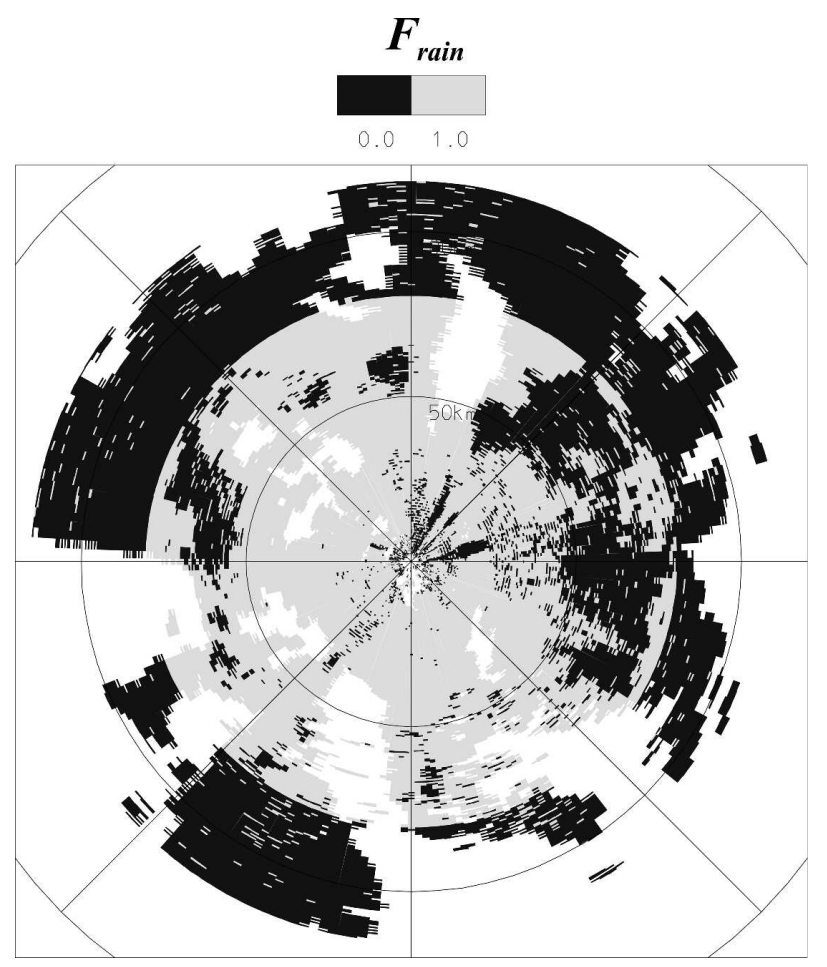

FIG. 16. Quality-index field $F_{\text {rain }}$ identifying areas consisting mainly of rain $\left(F_{\text {rain }}=1\right)$ and areas including other hydrometeor types $\left(F_{\text {rain }}=0\right)$. Calculations are based on the polarimetric parameters measured at 1520 UTC on 26 Jun 1997.

or snow by the classification scheme (Höller et al. 1994).

\section{e. Consistency check using $Z_{e}, Z D R$, and $K D P$}

The consistency check between $Z_{e}, \mathrm{ZDR}$, and KDP was originally proposed by Goddard et al. (1994) and in a different description by Scarchilli et al. (1996) in order to check the performance of radar systems within rain. Here $Z_{e}$ and ZDR are used to first derive the raindrop size distribution and then estimate KDP from the raindrop size distribution. The latter is denoted as K̂DP. If $\hat{K} D P$ and the measured KDP agree, the data are consistent.

An alternative approach was proposed by Gorgucci et al. (1998). They used $Z_{e}$ and ZDR in order to derive the attenuation in rain (denoted as $\alpha_{H}$ ). On the other hand, KDP can also be used to estimate the attenuation in rain (referred to as $\alpha_{H}^{*}$ ). If $\alpha_{H}$ and $\alpha_{H}^{*}$ agree, the measurements of $Z_{e}, \mathrm{ZDR}$, and KDP are considered to be consistent. Differences between K̂P - KDP and $\alpha_{H}-\alpha_{H}^{*}$ result from calibration errors or wrong assumptions concerning scattering properties and size distribution of raindrops (Gorgucci et al. 1998). The consistency check, however, will fail for hydrom- 


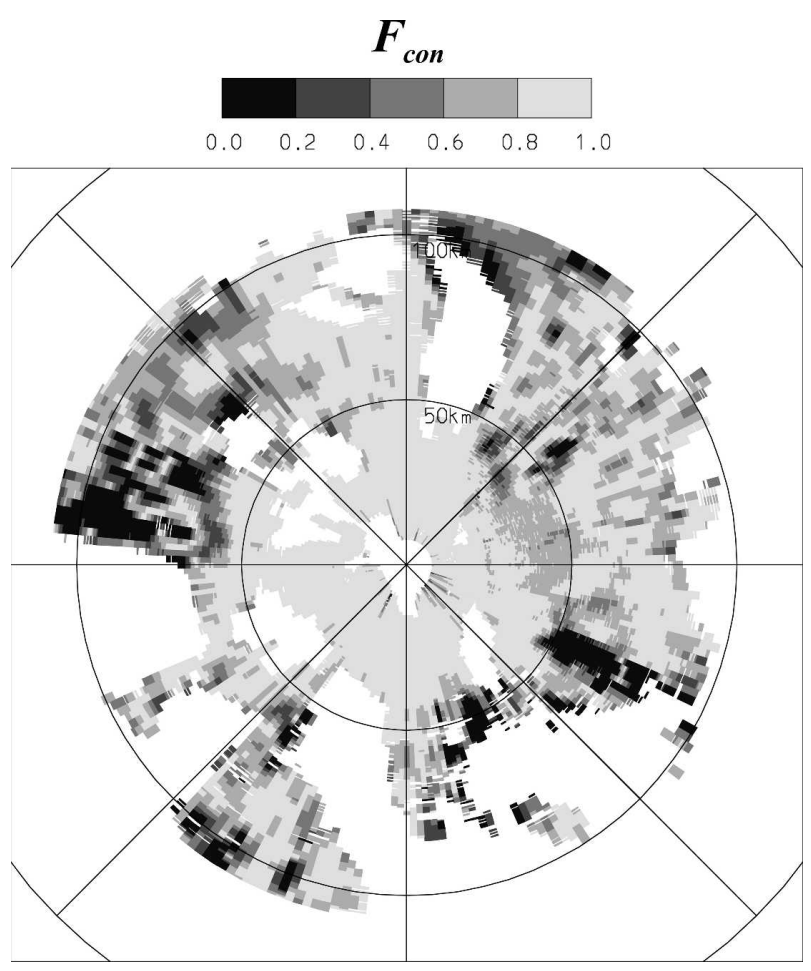

FIG. 17. Quality-index field $F_{\text {con }}$ illustrating the results of the consistency check between $Z_{e}, \mathrm{ZDR}$, and KDP. Calculations are based on polarimetric parameters measured at 1520 UTC on 26 Jun 1997.

eteor types other than rain since up to now it is only defined for rain. It also will fail for strong attenuation that is not considered by the procedure proposed by Gorgucci et al. (1998).

The quality-index field $F_{\text {con }}$ can be computed as

$$
\begin{aligned}
& F_{\text {con }}= \begin{cases}1 & \text { for } e<e_{\min } \\
0 & \text { for } e>e_{\max } \\
\frac{e_{\max }-e}{e_{\max }-e_{\min }} & \text { else, }\end{cases} \\
& e=|\hat{\mathrm{KDP}}-\mathrm{KDP}| \text {, }
\end{aligned}
$$

where $e_{\min }$ and $e_{\max }$ are the thresholds for minimum and maximum KDP difference. The interpolation between $F_{\text {con }}$ and $e$ is schematically indicated in Fig. 13c.

The quality-index field $F_{\text {con }}$ for the polarimetric parameters measured on 26 June 1997 is illustrated in Fig. 17. The thresholds $e_{\min }$ and $e_{\max }$ were set to $0^{\circ} \mathrm{km}^{-1}$ and $1^{\circ} \mathrm{km}^{-1}$, respectively. Low values of $F_{\text {con }}$ are observed in regions with ground clutter contamination and in regions where $F_{\text {rain }}=0$. Within stratiform precipitation $e_{\max }$ is set to about $0.5^{\circ} \mathrm{km}^{-1}$, which is equivalent to an error of about $10 \mathrm{~mm} \mathrm{~h}^{-1}$ for rainfall rate. For convective or hybrid cases, $e_{\max }$ is set to $1^{\circ}$ $\mathrm{km}^{-1}$ (Table 3).

Even though the consistency check is based on the assumption that rain is present, it will not necessarily fail if other particles than rain are dominant. This can be seen when comparing Figs. 16 and 17 beyond the $80-\mathrm{km}$ range where temperatures are below $0^{\circ} \mathrm{C}$. Here $F_{\text {con }}$ is above 0.8 north-northwest of the radar where ice is present as indicated by low $Z_{e}$, ZDR, and KDP values. For rain-rate estimation $\overline{F_{P}}$ is set to zero when $F_{\text {rain }}$ $=0$. Furthermore, the estimation of KDP requires an integration of the differential phase over a certain range interval. Gorgucci et al. (1998) used an interval of $12 \mathrm{~km}$, while an interval of $8 \mathrm{~km}$ was chosen for the 26 June 1997.

\section{f. Average quality-index field for polarimetric radar products}

In Fig. 18a the average quality-index field is shown for polarimetric radar products observed on 26 June 1997. This case is assumed to have hybrid character with stratiform precipitation and embedded convection. Weights and thresholds were set according to the values for rain-rate estimation within hybrid cases (Tables 1 and 3). Observations were taken up to a range of $120 \mathrm{~km}$ on that day. Since $\overline{F_{P}}$ is set to zero when no rain is detected $\left[F_{\text {rain }}=0\right.$ in Eq. (11)], the influence of $F_{\text {rain }}$ dominates the average quality-index field shown in Fig. 18a.

Figure $18 \mathrm{~b}$ shows the weighing factor combination when polarimetric products like hydrometeor classification are used for nowcasting purposes or when water and ice content are assimilated into NWP models In those cases, $W_{\text {bea }}$ is set to 0.5 , while $W_{\text {rain }}$ and $W_{\text {con }}$ remain zero (Table 1 ). In this case, $\overline{F_{P}}$ is dominated by a combination of beam broadening, beam shielding, and attenuation as expressed by $F_{\text {range }}, F_{\text {shield }}$, and $F_{\text {att }}$.

\section{Quality-index scheme for Doppler velocity}

\section{a. Methodology}

The quality of Doppler velocity is more related to the quality of the phase measurement and contaminations by moving non-weather-related objects. Nevertheless, beam broadening and ground clutter contamination, as listed as field (1) and (2) for reflectivity, can indeed affect the quality of Doppler velocity measurements and are also applied for the quality-index field for Doppler velocity measurements. The following qualityindex fields are monitored and encoded:

1) beam broadening (denoted as $F_{\text {range }}$ ),

2) partial or complete beam shielding due to ground clutter (denoted as $F_{\text {shield }}$ ),

3) standard deviation of the Doppler velocity (denoted as $\left.F_{\sigma_{v}}\right)$, 
(a)

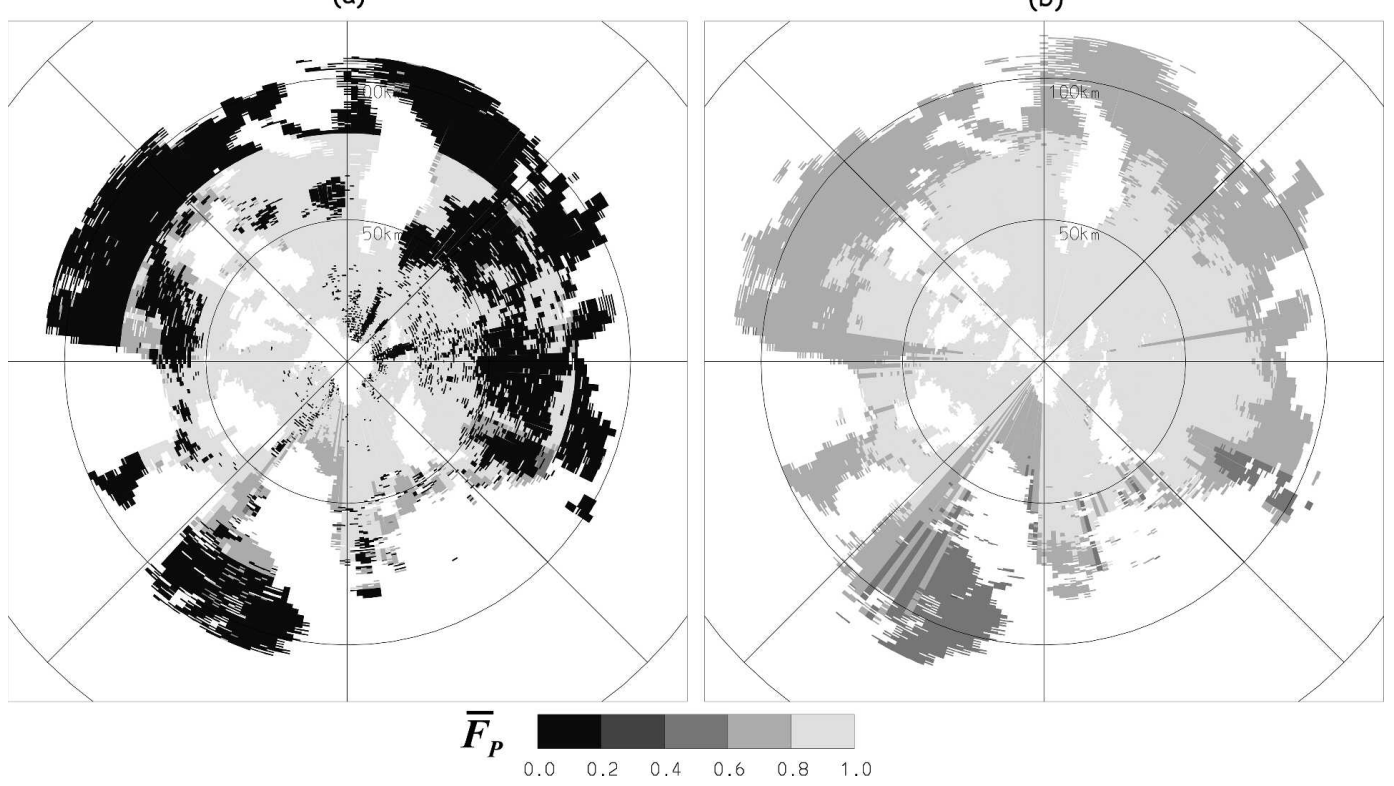

FIG. 18. Average quality-index field $\bar{F}_{P}$ for polarimetric parameters measured at $1^{\circ}$ elevation at $1520 \mathrm{UTC}$ on 26 Jun 1997: (a) all weights are equally set to one; (b) $\bar{F}_{P}$ with $W_{\text {bea }}=0.5, W_{\text {rain }}=W_{\text {con }}=0$, and $W_{\text {res }}=W_{\text {gclu }}=$ $W_{\text {att }}=1$
4) nonprecipitating clutter contamination due to birds, chaff, airplanes (denoted as $F_{\text {np }}$ ).

Again, the quality-index fields 1 and 2 for Doppler velocity are constant for a given installation and indepen- dent of weather situation, while all other fields are calculated for each radar volume separately.

The averaged quality-index fields for Doppler velocity $\bar{F}_{v_{r}}$ are computed as

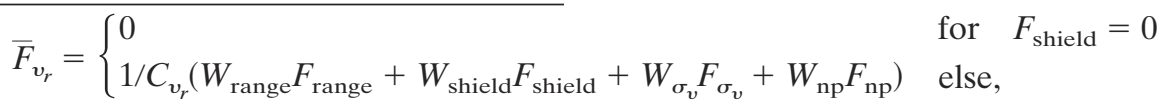

where

$$
C_{v_{r}}=W_{\text {range }}+W_{\text {shield }}+W_{\sigma_{v}}+W_{\text {np }}
$$

with $W_{\text {range }}, W_{\text {shield }}, W_{\sigma_{v}}$, and $W_{\text {np }}$ being the respective weights. Table 1 gives an overview about weighting factor ranges, which will be discussed in more detail in the following sections.

When the radar beam is shielded completely by ground clutter $\left(F_{\text {shield }}=0\right)$, the quality-index field for Doppler velocity data $\bar{F}_{v_{r}}$ becomes zero. The interpolation from the respective parameter field to the qualityindex field is illustrated in Figs. 3a,b and Fig. 19, respectively. The quality of the Doppler velocity is analyzed for a measurement taken at 1536 UTC on 25 October 1999 during a stratiform precipitation event. Doppler velocity, spectrum width, and reflectivity are illustrated in Fig. 20. The stratiform precipitation is characterized by a homogeneously distributed wind field with low turbulence and low wind shear showing spectrum width values mainly below $2 \mathrm{~m} \mathrm{~s}^{-1}$. Only at a range of 40-50 km northeast, north-northwest, and west of POLDIRAD, does the spectrum width have values higher than $2 \mathrm{~m} \mathrm{~s}^{-1}$. Reflectivities range between 20 and $40 \mathrm{~dB} Z$.

\section{b. Utilizing beam broadening and ground clutter contamination}

The broadening of the radar beam causes an increase in spatial resolution resulting in smoothing small-scale wind features such as vertical wind shear zones. Ground clutter contamination influences significantly the quality of the Doppler velocity measurement. A complete shielding of the main beam, that is, zero Doppler velocity return, can be detected and removed usually during signal processing. When the beam is shielded completely by ground clutter, the main power is blocked and the backscattering signal comes from the pulse volume edges that are located at a higher eleva- 


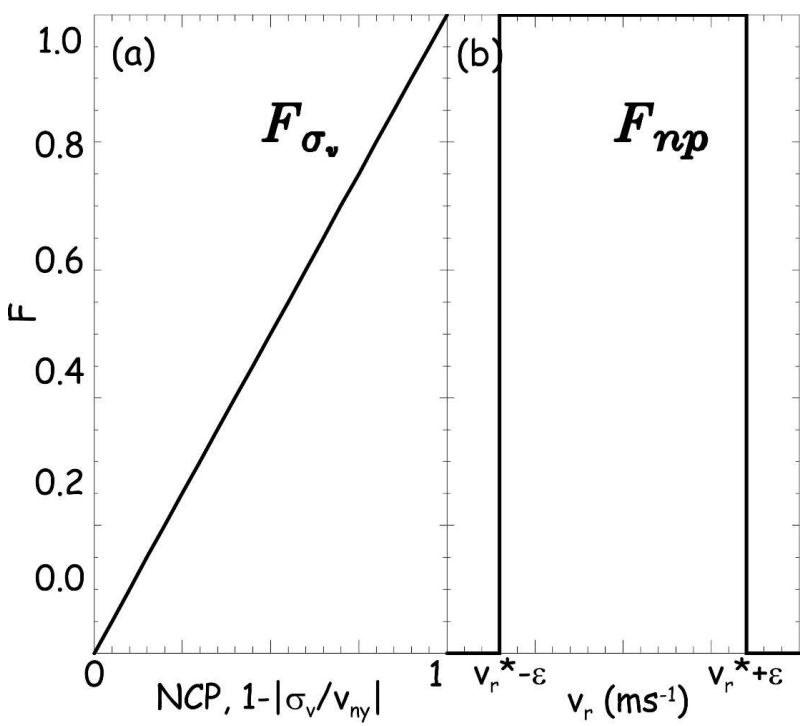

FIG. 19. Computation of the quality-index fields for Doppler velocity based on (a) the standard deviation of the Doppler velocity expressed by the NCP or $\sigma_{\mathrm{v}}$ values $\left(F_{\sigma_{v}}\right)$ and (b) contamination due to nonprecipitating echoes $\left(F_{\mathrm{np}}\right)$. Contamination is detected when the Doppler velocity lies outside the interval of $\left[v_{r}^{*}-\varepsilon ; v_{r}^{*}+\varepsilon\right]$.

tion than the main axis of the radar beam (Fig. 6b). In the presence of vertical wind shear, the Doppler velocity measured at the pulse volume edge differs from that measured at the beam axis. When, for instance, $80 \%$ of the transmitted beam is shielded measurements are related only to the upper pulses' volume edge creating a height error for instance of about $0.35 \mathrm{~km}\left(0.4^{\circ}\right)$ at a distance of $50 \mathrm{~km}$ for a $1^{\circ}$ beamwidth. Assuming a vertical wind shear of $10 \mathrm{~m} \mathrm{~s}^{-1} \mathrm{~km}^{-1}$, the resulting velocity error is about $3.5 \mathrm{~m} \mathrm{~s}^{-1}$.

\section{c. Utilizing standard deviation of the Doppler velocity}

To estimate the standard deviation of the Doppler velocity measurement, the Doppler spectrum width $\sigma_{\mathrm{v}}$ is used. It is the second moment of the autocorrelation function taken from the Doppler power spectrum. The major contributions for broadening the Doppler power spectrum width are due to meteorological factors such as wind shear and turbulence. Weather situations with low wind shear and low turbulence result in a small spectrum width, and vice versa. For weather situations with homogeneous wind fields that occur for instance within stratiform precipitation, the quality of the Doppler velocity measurement will be quite high. For weather situations with high wind shear and turbulence, for example, in up- and downdraft in convective storms or low-level gust fronts, the spectrum width becomes very high due to the high variability of Doppler velocity within the resolution volume. Some radar systems, however, process normalized coherent power (NCP), which is related to the ratio between zeroth and first moment of the autocorrelation function. This value can be directly applied. According to NCP or $\sigma_{\mathrm{v}}$ the qualityindex field is linearly interpolated (Fig. 18a) as

$$
F_{\sigma v}=1-\left|\sigma_{v} / v_{\mathrm{nv}}\right|
$$

or alternatively

$$
F_{\sigma_{v}}=\mathrm{NCP}
$$

with $v_{\text {nv }}$ being the Nyquist velocity interval. Figure 21 depicts the quality-index field $F_{\sigma v}$ for the wind field on 25 October 1999 (Fig. 19). Areas of enhanced turbulence are visible between a range of $40-50 \mathrm{~km}$ west, north-northwest, and northeast of POLDIRAD.

\section{d. Utilizing non-weather-related objects}

Generally, hydrometeors or insects follow the airflow, so that backscattering echoes from those targets represent the wind velocity. On the other hand, Doppler radar measurements are often contaminated by other targets such as birds, ships, chaff, ground clutter, or airplanes. Based on the idea of the velocity-azimuth display (VAD) analysis (Lhermitte and Atlas 1961; Browning and Wexler 1968), Doppler velocities related to nonweather objects and failures of Doppler velocity dealiasing algorithms can be detected. With this quality-index scheme those objects that do not represent the current airflow are detected. In contrast to the VAD analysis, limitations due to the effect of inhomogeneities in precipitation fall speed, reflectivity distribution, or variation of the elevation angle can be neglected since this quality control focuses on gross errors that lie far outside the Doppler velocity standard deviation.

Doppler velocities along an entire scanned circle of constant range and elevation show a sinus-like shape. According to the VAD analysis, Doppler velocities $v_{r}$ along a constant range are fitted to the form

$$
\begin{aligned}
v_{r}(\alpha)= & C(0)+C(1) \sin (\alpha)+C(2) \cos (\alpha) \\
& +C(3) \sin (2 \alpha)+C(4) \cos (2 \alpha)
\end{aligned}
$$

using singular value decomposition in order to find least squares fits [a description can be found in Press et al. (1992, 665-675)]. Fitting coefficients are denoted as $C(0), C(1), C(2), C(3)$, and $C(4)$; azimuth angle is denoted as $\alpha$. A VAD of Doppler velocities together with the fitting function is shown in Fig. 22a based on the 25 October 1999 wind field. Doppler velocities that lie outside the standard deviation of the threshold (as illus- 
(a)

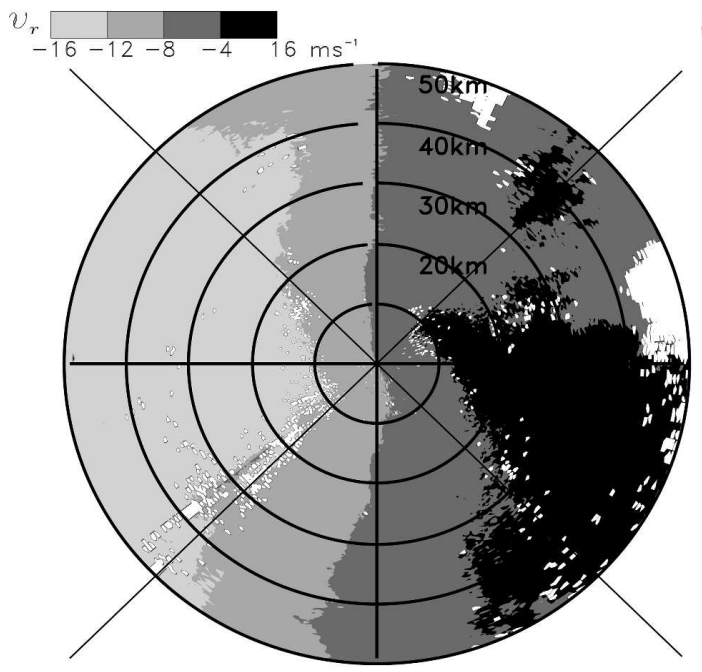

(b)

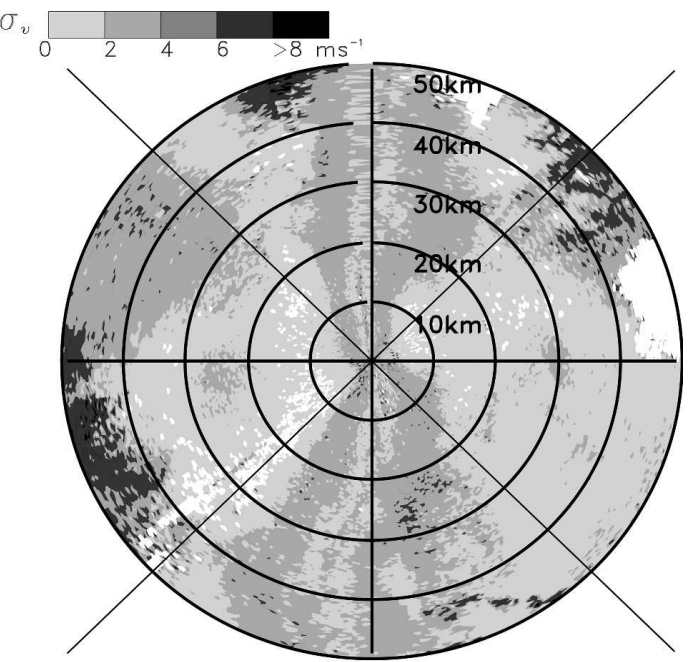

(c)

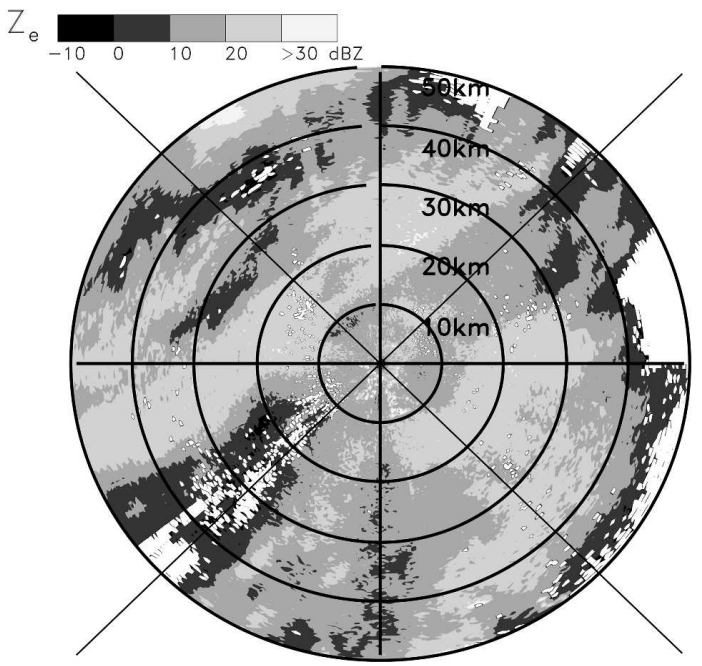

FIG. 20. PPI of (a) Doppler velocity $\left(v_{r}\right)$, (b) spectrum width $\left(\sigma_{\mathrm{v}}\right)$, and (c) reflectivity $\left(Z_{e}\right)$ at $1^{\circ}$-elevation angle. Measured were achieved by POLDIRAD (located in the center) at 1536 UTC on 25 Oct 1999. (a) Negative Doppler velocity indicates a movement toward the radar and positive away from the radar.

trated in Fig. 22a as thick, solid lines) are flagged as $F_{\mathrm{np}}$ $=0$. Therefore, the quality-index field is determined as

$$
F_{\mathrm{np}}= \begin{cases}1 & \text { for } \quad v_{r}^{*}(\alpha)-\varepsilon \leq v_{r}(\alpha) \leq v_{r}^{*}(\alpha)+\varepsilon \\ 0 & \text { else }\end{cases}
$$

while $\varepsilon$ is set to $4 \mathrm{~m} \mathrm{~s}^{-1}$. The fitting function based on the calculated fitting coefficients (illustrated in Fig. 22a as thick, dashed lines) is denoted as $v_{r}^{*}(\alpha)$. An illustration of $F_{\text {np }}$ is given in Fig. 22b for Doppler velocities measured on 25 October 1999 (Fig. 20a). For wind fields within stratiform precipitation the threshold is set to one-fourth of the Nyquist velocity interval. For more turbulent wind fields, for example, during convective weather, the threshold is increased to one-half of the Nyquist velocity for all applications.

\section{e. Average quality-index field for Doppler velocity}

To determine the quality of Doppler velocity measurements, the four separately calculated quality-index fields are weighted and averaged according to Eq. (13). Both $F_{\text {range }}$ and $F_{\text {shield }}$ are calculated according to Eqs. (2) and (6). On that day, data were only available up to 


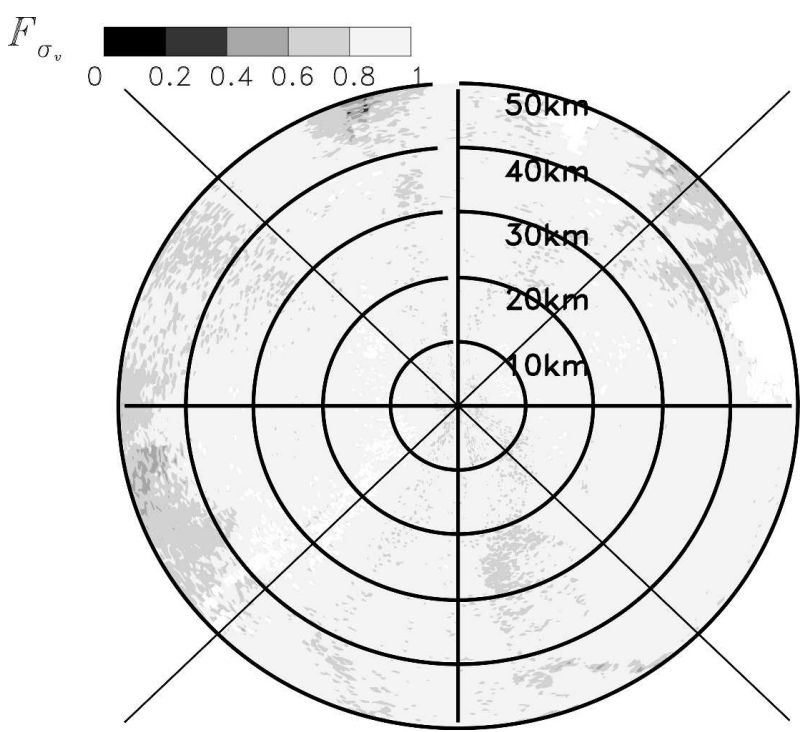

FIG. 21. Quality-index field illustrating the standard deviation of the Doppler velocity $\left(F_{\sigma_{v}}\right)$. Calculations are based on the spectrum width measurements taken at 1536 UTC on 25 Oct 1999 (Fig. 20b).

a range of $50 \mathrm{~km}$, which is used as the maximum range $r_{\max }$. Doppler velocity and the average quality-index field for the 25 October 1999 case are presented in Fig. 23. All weights are set to one; that is, the impact of each error source on the overall quality is treated equally. Most of the measurements with $\bar{F}_{v_{r}}<0.2$ are contaminated by ground clutter located within the vicinity of the radar. The standard deviation of the Doppler velocity is low (Fig. 21), and only a small amount of nonweather-related objects are detected (Fig. 22b). Therefore, the impact of range resolution and ground clutter on $\bar{F}_{v_{r}}$ became more pronounced. The former is indicated by a decrease of $\bar{F}_{v_{r}}$ in radial direction and being constant in azimuthal direction. Besides the areas having ground clutter contamination, the quality of the Doppler velocity measurements is very high.

Generally, the influence of each quality-index field to the average can be treated similar as listed in Table 1. Solely during weather situations having turbulent winds, the detection of non-weather-related objects can become difficult since the wind field can have similar discontinuity structures as they were observed during bird migration. In this case, we suggest reducing the influence of $F_{\text {np }}$ on the average to range between about 0.6 and 0.8 . Consequently, $W_{\text {np }}$ should also be lowered slightly in weather situations consisting of both convective and stratiform precipitation (Table 1).

\section{Conclusions}

A concept for a quality control scheme for radar reflectivity, polarimetric parameters, and Doppler veloc- ity has been presented in this paper. It consists of two main parts: 1) filtering of gross irregularities and recovery of dealiased Doppler velocities or second-trip echoes and 2) quality control procedures based on a pixelby-pixel basis. The latter part is the focus of this paper. The concept of quantifying factors contributing to uncertainties in radar measurements and then transforming these into quality-index fields is demonstrated using very simple detection and quantification algorithms. Since the quality of the indices strongly depends on the quality of the detection algorithm, for example, for ground clutter or attenuation, we suggest that more sophisticated approaches or algorithms are used that are already tested or implemented in the particular radar system. The scheme is set up in a modular way allowing the extension, modification, and omission of algorithms. The average three-dimensional qualityindex fields for reflectivity, polarimetric parameters, and Doppler velocity can be easily transferred with the measurements and can be easily interpreted either by a nontrained end user or an automated scheme that generates radar products.

For reflectivity measurements main factors leading to uncertainties are the increase in resolution with range, beam shielding from ground clutter, attenuation of the electromagnetic wave by hydrometeors, and inhomogeneous vertical profile of reflectivity. The quality of polarimetric parameters is quantified by determining range resolution, beam shielding, the amount of attenuation, homogeneous beam filling, discriminating rain from other hydrometeors, and applying a consistency check between $Z_{e}$, ZDR, and KDP. Main factors quantifying the quality of Doppler velocity measurements are the spatial resolution, beam shielding, contamination from nonmeteorological targets, and utilizing the standard deviation.

The bias quantification depends mainly on thresholds marking lower and upper contamination limits. The influence of each quality index on the averaged field is quantified by weighting factors. Both thresholds and weighting factors rely on the application, the location of the radar and its relation to regional geography, and the weather situation. Most of the threshold limits and weights are either based on empirical findings or physical reasoning. This paper gives an example for a polarimetric C-band Doppler radar located in the Alpine foreland. Thresholds and weighting factors for this radar site are listed in Tables 1 and 3 for different applications and weather situations. Figure 24 shows the reflectivity field of the convective precipitation case measured on 21 July 1992 and the quality-index fields for rain-rate estimation, assimilation, and nowcasting application. 
(a)

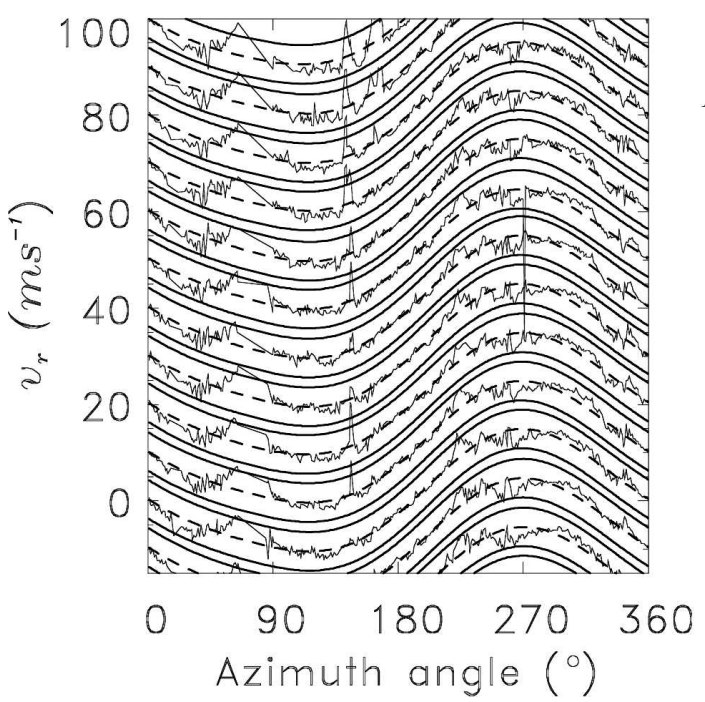

(b)

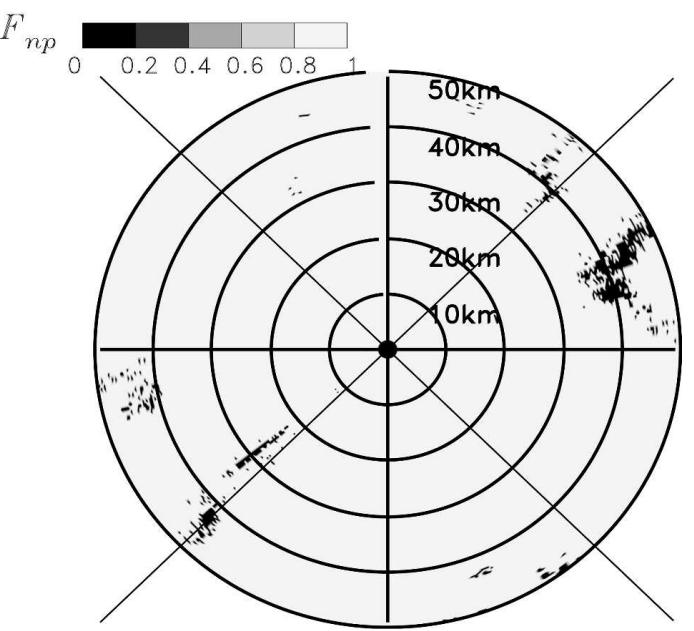

FIG. 22. (a) VAD of the Doppler velocity along the $360^{\circ}$ azimuth angle (thin, solid lines) together with the fitted sine curve (thick, dashed lines). Illustrated are measurements between a range of 46.5 and $49.8 \mathrm{~km}$ plotted with 10 $\mathrm{m} \mathrm{s}^{-1}$ offsets with the 46.8-km range centered around $v_{r}=0 \mathrm{~m} \mathrm{~s}^{-1}$. The threshold $\varepsilon \pm 4 \mathrm{~m} \mathrm{~s}^{-1}$ is displayed as thick, solid lines. (b) Quality-index field $F_{\text {np }}$ detecting returns related to nonprecipitating echoes for the 25 Oct 1999 case.

The proposed method can also be applied to radars operating at different transmitting frequencies and beamwidths, and located at different orographic or climatic regions. The impact of attenuation as intermittent bias increases with increasing transmitted frequency and increasing reflectivity. Attenuation should not be underestimated as shown by Bellon et al. (1997) for the $\mathrm{X}$ band within the melting layer and Zrnic and
Ryzhkov (1999) for S-band frequencies along a squall line. As a consequence the impact of attenuation can be reduced by lower values of $W_{\text {att }}$. Uncertainties due to increasing resolution, beam shielding, and inhomogeneous vertical reflectivity profile will decrease for decreasing beamwidth; that is, $W_{\text {range }}, W_{\text {shield }}$, and $W_{\text {vpr }}$ can be reduced. Although the impact of sea clutter was not discussed in this paper, it certainly occurs along (a)

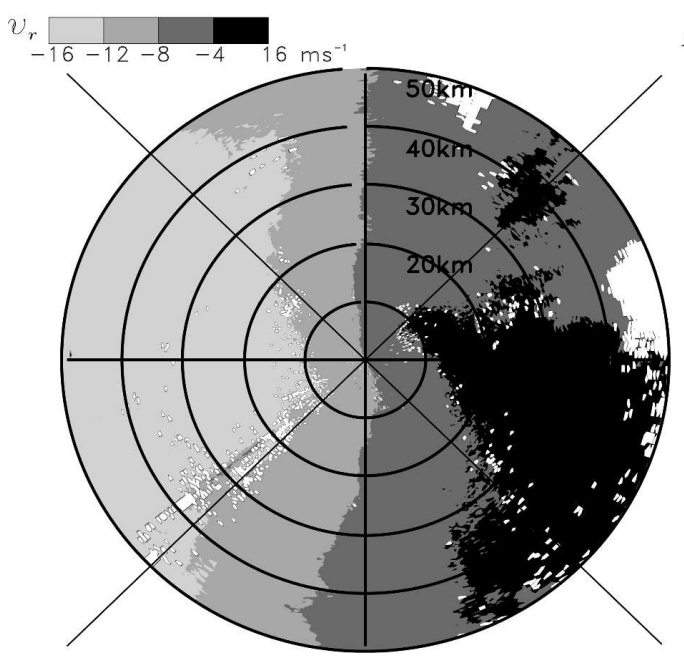

(b)

FIG. 23. (a) Doppler velocity $\left(v_{r}\right)$ as presented in Fig. 20a and (b) the resulting average quality control field $\left(\bar{F}_{v_{r}}\right)$ for the 25 Oct 1999 case. The impact of each error source is treated equally by setting all weights to one. 
(a)

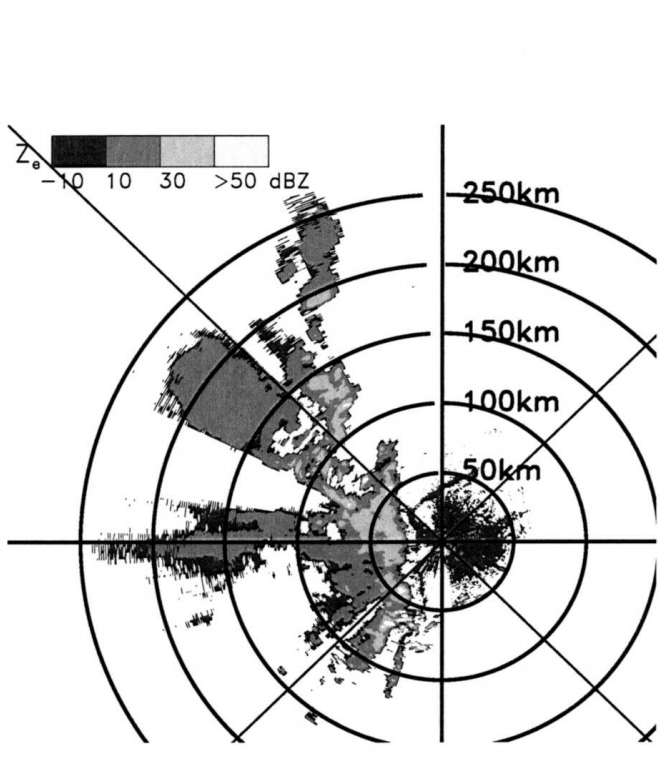

(c)

Assimilation into NWP models:

$W_{\text {res }}=W_{\text {att }}=1, W_{\text {gclu }}=0.8, W_{v p r}=0.8$

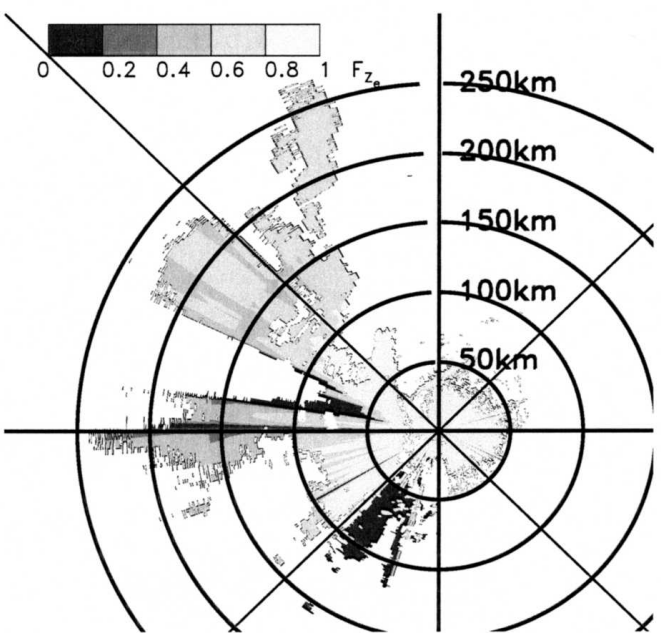

Rain rate estimation:

(b)

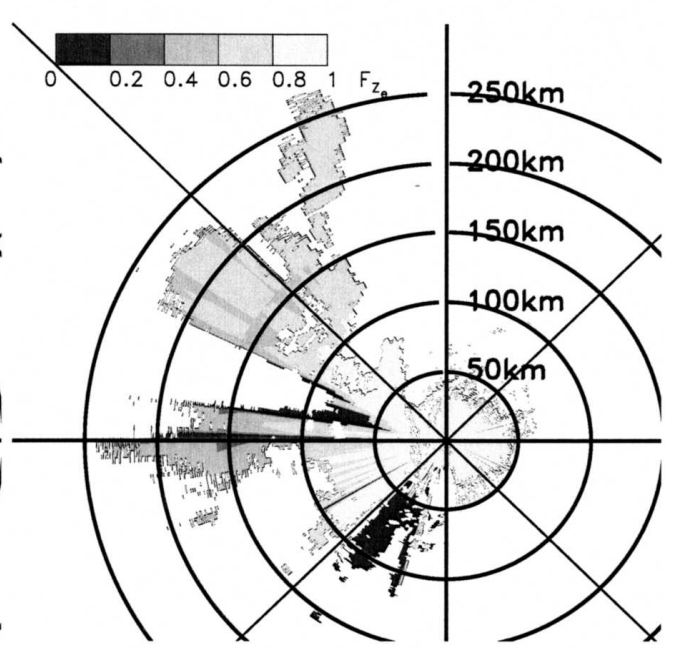

(d)

Nowcasting:

$$
W_{\text {res }}=1, W_{g c l u}=W_{a t t}=0.8, W_{v p r}=0
$$

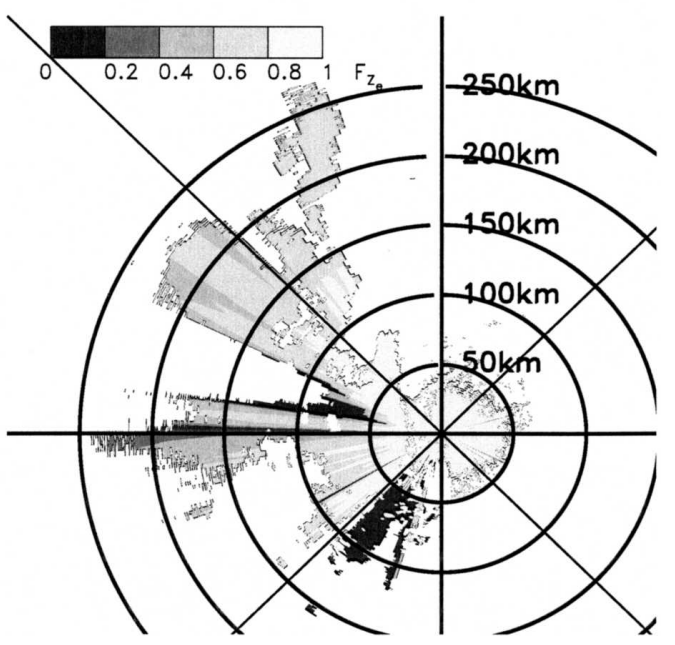

FIG. 24. (a) Reflectivity field $\left(Z_{e}\right)$ measured on 21 Jul 1992 as illustrated in Fig. 1 and (b), (c), (d) average quality-index fields $\bar{F}_{Z_{e}}$ applying different weighting factor combination.

coastal regions. The distinction between prevailing precipitation types (e.g., convective, stratiform, or hybrid), the performance of the quality index quantifying the inhomogeneous vertical reflectivity profile with varying height of the bright band, and the impact of the discrimination between rain and other precipitation types have to be adjusted according to the climatic conditions. Quality-index fields can also be combined to a composite map for radar networks in the same way as reflectivity maps.
Up to now this quality control has been operated only in a research mode and for a C-band radar. A precise evaluation of different weighting factors for different applications and weather situations will show what improvements can be achieved using this quality control scheme. In the next step, the propagation of the quality information through forecasting networks such as atmospheric and hydrological numerical models will be evaluated in the subsequent European COST Action 731 and the Mesoscale Alpine Program Forecast 
Demonstration Project (MAP D-PHASE) under the aegis of the World Meteorological Organization (WMO) World Weather Research Program (WWRP).

Acknowledgments. First we thank all the members of the COST 717 Working Group 3, especially Daniel Michaelson, Iwan Holleman, and Andrea Rossa. Without the encouraging discussions about error sources, user requirements, and realistic realization within an operational requirement, we would not be able to assemble this quality control concept. We extend special thanks to the three anonymous reviewers for providing comments and suggestions that enhanced the quality of the paper.

\section{REFERENCES}

Alberoni, P. P., and Coauthors, 2002: Quality and assimilation of radar data for NWP-A review. COST 717 Working Doc. EUR 20600, 38 pp. [Available online at http://www.smhi.se/ cost717/.]

Aniol, R., J. Riedl, and M. Dieringer, 1980: Ueber kleinraeumige und zeitliche Variationen der Niederschlagsintensitaet. Meteor. Rdsch., 33, 50-56.

Aydin, K., Y. Zhao, and T. A. Seliga, 1989: Rain-induced attenuation effects on C-band dual-polarization meteorological radars. IEEE Trans. Geosci. Remote Sens., 27, 57-66.

Battan, L. J., 1973: Radar Observation of the Atmosphere. The University of Chicago Press, 324 pp.

Bellon, A., I. Zawadzki, and F. Fabry, 1997: Measurements of melting layer attenuation at X-band frequencies. Radio Sci., 32, 943-955.

Berenguer, M., G. W. Lee, D. Sempere-Torres, and I. Zawadzki, 2002: A variational method for attenuation correction of radar signal. Preprints, European Conf. on Radar Meteorology, Delft, Netherlands, European Meteorological Society and Copernicus Gesellschaft mbH, 11-16.

Bringi, V. N., V. Chandrasekar, N. Balakrishnan, and D. S. Zrnic, 1990: An examination of propagation effects in rainfall on radar measurements at microwave frequencies. J. Atmos. Oceanic Technol., 7, 829-840.

Browning, K. A., and R. Wexler, 1968: The determination of kinematic properties of a wind field using Doppler radar. $J$. Appl. Meteor., 7, 105-113.

Chandrasekar, V., and R. J. Keeler, 1993: Antenna pattern analysis and measurements for multiparameter radars. J. Atmos. Oceanic Technol., 10, 674-683.

Dazhang, T., S. G. Geotis, R. E. Passarelli Jr., A. L. Hansen, and C. L. Frush, 1982: Evaluation of an alternating-PRF method for extending the range of unambiguous Doppler velocity. Preprints, 22nd Int. Conf. on Radar Meteorology, Zurich, Switzerland, Amer. Meteor. Soc., 523-527.

Delrieu, G., J. Creutin, and H. Andrieu, 1995: Simulation of radar mountain returns using a digitized terrain model. J. Atmos. Oceanic Technol., 12, 1038-1049.

Doviak, J. R., and D. S. Zrnic, 1992: Doppler Radar and Weather Observations. 2d ed. Academic Press, 562 pp.

Einfalt, T., K. Arnbjerg-Nielsen, C. Golz, N. E. Jensen, M. Quirmbach, G. Vaes, and B. Vieux, 2004: Towards a roadmap for use of radar rainfall data use in urban drainage. J. Hydrol., 299, 186-202.

Evans, J. E., and E. R. Ducot, 1994: The Integrated Terminal Weather System (ITWS). Lincoln Lab. J., 7, 449-474. [Available online at http://www.ll.mit.edu/AviationWeather/ evansitws.pdf.]

Friedrich, K., and M. Hagen, 2004: Wind synthesis and quality control of multiple-Doppler-derived horizontal wind fields. $J$. Appl. Meteor., 43, 38-57.

Gabella, M., and R. Notarpietro, 2002: Ground clutter characterization and elimination in mountainous terrain. Preprints, Second European Conf. on Radar Meteorology, Delft, Netherlands, European Meteorological Society and Copernicus Gesellschaft mbH, 305-311.

Giuli, D., M. Gherardelli, A. Freni, T. Seliga, and K. Aydin, 1991: Rainfall and clutter discrimination by means of dual-linear polarization radar measurements. J. Atmos. Oceanic Technol., 8, 777-789.

Goddard, J. W. F., J. Eastment, and J. Tan, 1994: Self consistent measurements of differential phase and differential reflectivity in rain. Preprints, IGARSS 1994, Pasadena, CA, IEEE, 369-371.

Golz, C., T. Einfalt, and M. Jessen, 2004: Radar data quality control procedures. Preprints, Third European Conf. on Radar Meteorology, Visby, Sweden, 435-437.

Gorgucci, E., G. Scarchilli, and V. Chandrasekar, 1996: Error structure of radar rainfall measurement at C-band frequencies with dual polarization algorithm for attenuation correction. J. Geophys. Res., 101, 26 461-26 471.

,,,--- P. Meischner, and M. Hagen, 1998: Intercomparison of techniques to correct for attenuation of C-band weather radar signals. J. Appl. Meteor., 37, 845-853.

Grecu, M., and W. F. Krajewski, 2000: An efficient methodology for detection of anomalous propagation echoes in radar reflectivity data using neutral networks. J. Atmos. Oceanic Technol., 17, 121-129.

Hagen, M., 1997: Identification of ground clutter by polarimetric radar. Preprints, 28th Int. Conf. on Radar Meteorology, Austin, TX, Amer. Meteor. Soc., 67-68.

Hannesen, R., 2001: Quantitative precipitation estimation from radar data-A review of current methodologies. Deliverable 4.1 for the research project MUSIC supported by the European Commission, $31 \mathrm{pp}$. [Available online at http:// www.geomin.unibo.it/orgv/hydro/music/reports/D4.1 QPErevi.pdf.]

Holleman, I., and H. Beekhuis, 2003: Analysis and correction of dual PRF velocity data. J. Atmos. Oceanic Technol., 20, $443-$ 453.

Höller, H., V. N. Bringi, J. Hubbert, M. Hagen, and P. F. Meischner, 1994: Life cycle and precipitation formation in a hybrid-type hailstorm revealed by polarimetric and Doppler radar measurements. J. Atmos. Sci., 51, 2500-2522.

Illingworth, A. J., 2003: Improved precipitation rates and data quality by using polarimetric measurements. Weather Radar: Principles and Advanced Applications, P. Meischner, Ed., Springer-Verlag, 130-166.

James, C. N., and R. A. Houze, 2001: A real-time fourdimensional Doppler dealiasing scheme. J. Atmos. Oceanic Technol., 18, 1674-1683.

Joss, J., and R. Lee, 1995: The application of radar-gauge comparisons to operational precipitation profile corrections. $J$. Appl. Meteor., 34, 2612-2630.

— 
of radar for precipitation measurements in Switzerland. Tech. Rep., vdf Hochschulverlag AG an der ETH Zuerich, 108 pp.

Kessinger, C., S. Ellis, J. van Andel, J. Hubbert, and R. J. Keeler, 2003: NEXRAD data quality optimization. Tech. Rep., Research Application Program/Atmospheric Technology Division, National Center of Atmospheric Research, 70 pp. [Available online at http://www.atd.ucar.edu/rsf/NEXRAD/ index.htm.]

Krajewski, W. F., and B. Vignal, 2001: Evaluation of anomalous propagation echo detection in WSR-88D data: A large sample case study. J. Atmos. Oceanic Technol., 18, 807-814.

Lang, P., 2001: Cell tracking and warning indicators derived from operational radar products. Preprints, 30th Int. Conf. on Radar Meteorology, Munich, Germany, Amer. Meteor. Soc., 245-247.

Lee, R., G. D. Bruna, and J. Joss, 1995: Intensity of ground clutter and of echoes of anomalous propagation and its elimination. Preprints, 27th Conf. on Radar Meteorology, Vail, CO, Amer. Meteor. Soc., 651-652.

Lhermitte, R. M., and D. Atlas, 1961: Precipitation motion by pulse Doppler. Preprints, Ninth Weather Radar Conf., Boston, MA, Amer. Meteor. Soc., 498-503.

Meischner, P., Ed., 2003: Weather Radar: Principles and Advanced Applications. Springer-Verlag, $300 \mathrm{pp}$.

Parent du Châtelet, J., P. Tabary, and M. Guimera, 2005: The Panthere Project and the evolution of the French operational radar network and products: Rain-estimation, Doppler winds, and dual-polarisation. Preprints, $32 d$ Conf. on Radar Meteorology, Albuquerque, NM, Amer. Meteor. Soc., CDROM, 14R.6.

Pierce, C. E., P. J. Hardaker, C. G. Collier, and C. M. Haggett, 2000: Gandolf: A system for generating automated nowcasts of convective precipitation. Meteor. Appl., 7, 341-360.

Press, W. H., S. A. Teukolsky, W. T. Vetterling, and B. P. Flannery, 1992: Numerical Recipes in Fortran 77. 2d ed. Cambridge University Press, 933 pp.

Richter, C., and M. Hagen, 1997: Dropsize distributions of raindrops by polarisation radar and simultaneous measurements with disdrometer, windprofiler and pms-probes. Quart. J. Roy. Meteor. Soc., 123, 2277-2296.

Rossa, A., M. Bruen, D. Fruehwald, B. MacPherson, I. Hollemann, D. Michaelson, and S. Michaelides, 2005: Use of radar observations in hydrological and NWP models. COST 717 Working Doc., 292 pp. [Available online at http://www.smhi. se/cost717/.]

Ryzhkov, A., and D. Zrnic, 1998: Beamwidth effects on the differential phase measurements of rain. J. Atmos. Oceanic Technol., 15, 624-634.

Sachidananda, M., 1997: Signal design and processing techniques for WSR-88D ambiguity resolution. Part 1. Tech. Rep. NOAA/NSSL, 100 pp.

Sanchez-Diezma, R., D. Sempere-Torres, G. Delrieu, and I. Zawadzki, 2001: An improved methodology for ground clut- ter substitution based on a pre-classification of precipitation types. Preprints, 30th Int. Conf. on Radar Meteorology, Munich, Germany, Amer. Meteor. Soc., 271-273.

Scarchilli, G., E. Gorgucci, V. Chandrasekar, and A. Dobaie, 1996: Self-consistency of poarization diversity measurement of rainfall. IEEE Trans. Geosci. Remote Sens., 34, 22-26.

Seliga, T. A., and V. N. Bringi, 1976: Potential use of radar differential reflectivity measurements at orthogonal polarization for measuring precipitation. J. Appl. Meteor., 15, 69-76.

Seltmann, E. E. J., 2000: Clutter versus radar winds. Phys. Chem. Earth, B25, 1173-1178.

Sempere-Torres, D., R. Sanchez-Diezma, M. Berenguer, R. Pascual, and I. Zawadzki, 2003: Improving radar rainfall measurement stability using mountain returns in real time. Preprints, 31st Int. Conf. on Radar Meteorology, Seattle, WA, Amer. Meteor. Soc., CD-ROM, 4B.4.

Sigmet, 2004: RVP8-Digital IF receiver/Doppler signal processor: User's manual. Sigmet, 409 pp. [Available online at http://www.sigmet.com.]

Steiner, M., and J. A. Smith, 2002: Use of three-dimensional reflectivity structure of automated detection and removal of nonprecipitating echoes in radar data. J. Atmos. Oceanic Technol., 19, 673-686.

Tabary, P., G. Scialom, and U. Germann, 2001: Real-time retrieval of the wind from aliased velocities measured by Doppler radars. J. Atmos. Oceanic Technol., 18, 875-882.

Torlaschi, E., and I. Zawadzki, 2003: The effect of mean and differential attenuation on the precision and accuracy of the estimates of reflectivity and differential reflectivity. J. Atmos. Oceanic Technol., 20, 362-371.

Unal, C. M. H., and D. N. Moisseev, 2004: Combined Doppler and polarimetric radar measurements: Correction for spectrum aliasing and nonsimultaneous polarimetric measurements. $J$. Atmos. Oceanic Technol., 21, 443-456.

Vivekanandan, J., D. S. Zrnic, S. M. Ellis, R. Oye, A. V. Ryzhkov, and J. Straka, 1999: Cloud microphysics retrieval using Sband dual-polarization radar measurements. Bull. Amer. Meteor. Soc., 80, 381-388.

Yuter, S. E., 2003: Precipitation radar. Encyclopedia of Atmospheric Sciences, J. R. Holton, J. Pyle, and J. Curry, Eds., 1833-1851.

Zawadzki, I., 1984: Factors affecting the precision of radar measurement of rain. Preprints, 22nd Conf. on Radar Meteorology, Zurich, Switzerland, Amer. Meteor. Soc., 251-256.

Zrnic, D. S., 1996: Weather radar polarimetry-Trends toward operational applications. Bull. Amer. Meteor. Soc., 77, 1529 1534.

_ , and P. Mahapatra, 1985: Two methods of ambiguity resolution in pulse Doppler weather radars. IEEE Trans. Aerosp. Elec. Syst., 4, 470-483.

, and A. V. Ryzhkov, 1999: Polarimetry for weather surveillance radars. Bull. Amer. Meteor. Soc., 80, 389-406. 